\title{
Soil moisture-atmosphere feedbacks mitigate declining water availability in drylands
}

\section{Sha Zhou ( $\nabla$ sz2766@columbia.edu )}

Lamont-Doherty Earth Observatory of Columbia University

\section{A. Park Williams}

Lamont-Doherty Earth Observatory of Columbia University

\section{Benjamin R. Lintner}

Department of Environmental Sciences, Rutgers, The State University of New Jersey

\section{Alexis M. Berg}

Department of Earth and Planetary Sciences, Harvard University

\section{Yao Zhang}

Lawrence Berkeley National Laboratory

\section{Trevor F. Keenan}

Department of Environmental Science, Policy and Management, UC Berkeley

\section{Benjamin I. Cook}

NASA Goddard Institute for Space Studies

\section{Stefan Hagemann}

Helmholtz-Zentrum Geesthacht, Institute of Coastal Research

\section{Sonia I. Seneviratne}

Institute for Atmospheric and Climate Science, ETH Zurich

\section{Pierre Gentine}

Department of Earth and Environmental Engineering, Columbia University

\section{Research Article}

Keywords: precipitation, evapotranspiration, thermodynamic, dynamic

Posted Date: November 17th, 2020

DOl: https://doi.org/10.21203/rs.3.rs-109572/v1

License: (9) This work is licensed under a Creative Commons Attribution 4.0 International License. Read Full License 
Version of Record: A version of this preprint was published at Nature Climate Change on January 1st, 2021. See the published version at https://doi.org/10.1038/s41558-020-00945-z. 
1 Soil moisture-atmosphere feedbacks mitigate declining water availability in drylands

2 Sha Zhou ${ }^{1,2,3,4,5^{*}}$, A. Park Williams ${ }^{1}$, Benjamin R. Lintner ${ }^{6}$, Alexis M. Berg ${ }^{7}$, Yao Zhang ${ }^{4,5}$,

3 Trevor F. Keenan ${ }^{4,5}$, Benjamin I. Cook ${ }^{1,8}$, Stefan Hagemann ${ }^{9}$, Sonia I. Seneviratne ${ }^{10}$, Pierre

4 Gentine ${ }^{2,3}$

5 'Lamont-Doherty Earth Observatory of Columbia University, Palisades, NY, USA

6 2Earth Institute, Columbia University, New York, NY, USA

$7{ }^{3}$ Department of Earth and Environmental Engineering, Columbia University, New York, NY,

8 USA

$9{ }^{4}$ Climate and Ecosystem Sciences Division, Lawrence Berkeley National Laboratory, Berkeley,

10 CA, USA

$11{ }^{5}$ Department of Environmental Science, Policy and Management, UC Berkeley, Berkeley, CA,

12 USA

$13{ }^{6}$ Department of Environmental Sciences, Rutgers, The State University of New Jersey, New

14 Brunswick, NJ, USA

$15{ }^{7}$ Department of Earth and Planetary Sciences, Harvard University, Cambridge, MA, USA

$16{ }^{8}$ NASA Goddard Institute for Space Studies, New York, NY, USA

$17{ }^{9}$ Helmholtz-Zentrum Geesthacht, Institute of Coastal Research, Geesthacht, Germany

$18{ }^{10}$ Institute for Atmospheric and Climate Science, ETH Zurich, Zurich, Switzerland

$19 *$ Correspondence to: sz2766@columbia.edu

21 Global warming alters surface water availability (precipitation minus evapotranspiration,

22 P-E) and hence freshwater resources. However, the influence of land-atmosphere feedbacks

23 on future P-E changes and the underlying mechanisms remain unclear. Here we demonstrate

24 that soil moisture (SM) strongly impacts future P-E changes, especially in drylands, by

25 regulating evapotranspiration and atmospheric moisture inflow. Using modeling and

26 empirical approaches, we find a consistent negative SM feedback on P-E, which may offset

$27 \sim \mathbf{6 0} \%$ of the decline in dryland P-E otherwise expected in the absence of SM feedbacks. The

28 negative feedback is not caused by atmospheric thermodynamic responses to declining SM,

29 but rather reduced SM, in addition to limiting evapotranspiration, regulates atmospheric

30 circulation and vertical ascent to enhance moisture transport into drylands. This SM effect

31 is a large source of uncertainty in projected dryland P-E changes, underscoring the need to 
32 better constrain future SM changes and improve representation of SM-atmosphere processes in models.

Future changes in water availability pose great challenges to global freshwater and food security and the sustainability of natural ecosystems ${ }^{1,2}$. Changes in precipitation and evapotranspiration are especially important for dryland ecosystems where vegetation growth and mortality largely depend on water availability ${ }^{3,4}$. Global warming is expected to intensify the global water cycle ${ }^{5-7}$, but the projected changes in surface water availability, namely precipitation minus evapotranspiration (PE), exhibit divergent spatial patterns between ocean and land ${ }^{8,9}$. Over the ocean, projected P-E changes broadly follow the "dry-get-drier, and wet-get-wetter" (DDWW) paradigm, driven by

42 increasing atmospheric moisture content and transport by the mean circulation in a warming 43 climate ${ }^{5,6}$. However, thermodynamic mechanisms cannot effectively explain P-E changes over 44 land, where the magnitudes of the P-E response to warming are much smaller than over the ocean ${ }^{8,9}$. 45 Circulation anomalies driven by sea surface temperature changes have been demonstrated to cause 46 deviations from the "wet-get-wetter" response in the wet tropics ${ }^{10-12}$, but the dynamic mechanisms 47 of dryland P-E changes, and their potential dependence on land surface feedbacks, are not well 48 understood.

In water-limited regions, soil moisture (SM) directly regulates evapotranspiration, which may 51 positively feed back onto precipitation via moisture recycling ${ }^{13,14}$. SM may also impact 52 precipitation through its influence on boundary layer dynamics and mesoscale circulations ${ }^{15-18}$.

53 For example, spatial gradients in SM and associated sensible heat flux gradients may preferentially 54 promote convection over drier soils relative to surrounding wetter soils, resulting in a negative SM 55 feedback on precipitation ${ }^{15,18,19}$. However, the sign of the SM-precipitation feedback can change 56 in the presence of a background wind that enables the propagation of convective cells to 57 neighboring regions ${ }^{20}$. Given that various processes may lead to short-term SM-precipitation 58 feedbacks of opposing sign and/or varying strength, it is challenging to extrapolate the effects of 59 these processes to longer timescales. The long-term (climatological) SM effects on P-E have yet 60 to be diagnosed, particularly under future global warming. 
62 Here we directly assess the long-term SM effect on future model-projected P-E using four general 63 circulation models included in the Global Land Atmosphere Coupling Experiment (GLACE)-

64 CMIP5 $^{21}$ as well as simulations from 35 general circulation models in CMIP5 (Methods and Table

65 S1). We quantify the SM contribution to P-E changes between 30-year historical (1971-2000) and future (2071-2100, RCP8.5) periods using three sets of model experiments in GLACE-CMIP5: a reference simulation (REF) with SM fully interactive with the atmosphere, and two perturbation simulations where SM climatology is prescribed as the 1971-2000 climatology (expA) and a centered, 30-year running mean climatology from REF (expB) (Extended Data Fig. 1). For each of the four models, the three simulations are driven by the same forcing agents (i.e., sea surface temperatures, sea ice, land use, and $\mathrm{CO}_{2}$ concentrations), allowing us to compare them to isolate

72 the total SM effect (REF-expA) and the effects of SM trends (expB-expA) and variability (REF-

73 expB) on P-E changes. We further develop a multiple linear regression model to assess the sign 74 and strength of the SM-(P-E) feedback and identify the primary feedback pathways by comparing 75 SM effects on atmospheric dynamic and thermodynamic processes using two observationally constrained reanalysis products (MERRA-2 and ERA5) that provide pressure level, wind and humidity data in recent decades (1979-2018). These pressure level data are not available in GLACE-CMIP5.

\section{Soil moisture effect on P-E changes in model projections}

81 The 35 CMIP5 models show significant ( $<<0.05$, Student's t-test) P-E increases in $42 \%$ of wet 82 regions and $\mathrm{P}-\mathrm{E}$ declines in $51 \%$ of dry regions over ocean between the historical and future 83 periods (Fig. 1a and Extended Data Fig. 2e). Over land, future P-E is projected to increase 84 significantly $(\mathrm{p}<0.05)$ in high-latitude wet regions, but its change is insignificant over $93 \%$ of dry regions. Here "dry" versus "wet" regions are characterized as negative versus positive P-E over ocean, and drylands versus non-drylands over land (Methods and Extended Data Fig. 2a-d). Unlike

87 P-E changes, significant $(\mathrm{p}<0.05)$ SM changes are projected over 33\% of drylands (Fig. 1b). Such 88 SM changes directly impact evapotranspiration and may potentially feed back onto precipitation, 89 both of which are expected to play a role in the projected P-E changes over land.

91 The spatial patterns of P-E and SM changes in REF of the four GLACE-CMIP5 models are largely 92 consistent with the broader suite of CMIP5 models (Fig. 1a-d and Extended Data Fig. 2e,f), with 
93 spatial correlation coefficients of 0.82 for P-E over all grid cells and 0.35 for SM. In expA, in

94 which the mean annual cycle of SM over the historical period is imposed throughout the entire

95 simulation, the DDWW paradigm holds over $31 \%$ of the land regions, compared to only $19 \%$ of

96 land areas showing DDWW in REF (Fig. 1c,e and Extended Data Fig. 2f,g). In particular, the

97 proportion of drylands showing significant $\mathrm{P}-\mathrm{E}$ declines in expA $(30 \%)$ is three times that in REF

98 (10\%). Since P-E changes in expA are driven by factors excluding SM trends and variability, such

99 as temperature-driven oceanic and atmospheric changes, we denote these factors collectively as 100 non-SM effects.

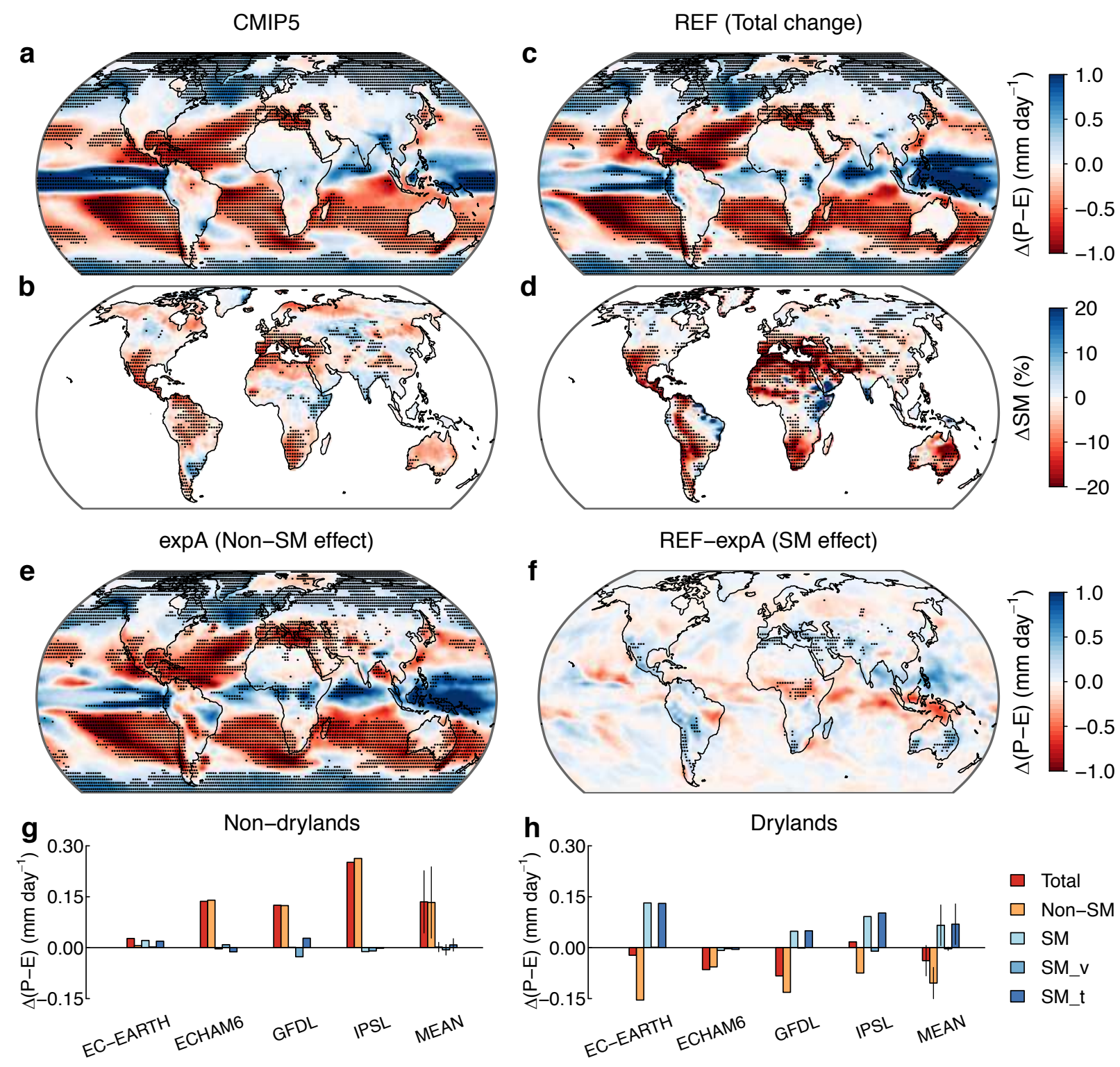

101

Fig. 1 | Multi-model mean annual changes in surface water availability and soil moisture. a- 
103 b, Changes in precipitation minus evapotranspiration $(\Delta(\mathrm{P}-\mathrm{E}))$ and percent changes in total soil moisture $(\triangle \mathrm{SM})$ between historical (1971-2000) and future (2071-2100, RCP8.5) periods (future minus historical values) in 35 CMIP5 models. c-f, The same as a-b, but for REF of the four GLACE-CMIP5 models (c-d), and $\Delta(\mathrm{P}-\mathrm{E})$ induced by non-SM factors (expA, e) and SM (REF$\operatorname{expA}, \mathbf{f}) \cdot \mathbf{g}-\mathbf{h}$, Total area-weighted $\Delta(\mathrm{P}-\mathrm{E})$ and the contributions from non-SM factors, total SM changes, SM variability (SM_v), and SM trends (SM_t) across non-drylands (g) and drylands (h) in the four GLACE-CMIP5 models. The error bar shows the standard deviation of $\Delta(\mathrm{P}-\mathrm{E})$ across the four models. Stippling denotes regions where the change in P-E is significant at the 95\% level (Student's t-test) and the sign of the change is consistent with the sign of multi-model means (as shown in the figure) in at least 21 of the 35 (60\%) CMIP5 models (a-b), and at least three of the four GLACE-CMIP5 models (c-f).

On the other hand, we isolate the SM effect on projected P-E changes by differencing the REF and expA simulations. The SM effects on projected P-E changes over land generally oppose the nonSM effects in expA (Fig. 1e,f), with spatial correlation coefficients ranging from -0.40 to -0.69 across the four models. The future SM changes and the P-E changes induced by SM are of opposite sign for multi-model means (Fig. 1d,f), and for each model (Extended Data Fig. 3) and season (Extended Data Fig. 4), indicating a negative SM feedback on P-E. P-E changes induced by nonSM factors are partially cancelled by the negative SM feedback on P-E, especially in drylands, where the SM-induced P-E increases in REF $(0.066 \pm 0.060 \mathrm{~mm} /$ day, mean \pm 1 s.d.) offset $63 \%$ of the P-E declines $(-0.104 \pm 0.046 \mathrm{~mm} /$ day $)$ that would be otherwise induced by the non-SM factors 124 simulated in expA (Fig. 1h). This offset effect is dominated by the negative SM trends over drylands (Fig. 1d), with minimal effect from changes in higher-frequency SM variability (Fig. 1h). The mitigating effect of declining SM on dryland P-E reduction is large in EC-EARTH (85\%), 127 GFDL (37\%) and IPSL (123\%), but no such effect is found in ECHAM6 because this model 128 projects increased SM that reduces P-E in many tropical drylands (Extended Data Fig. 3b,f,j). 129 Outside of drylands, P-E changes are generally dominated by non-SM factors (Fig. 1g).

131 Comparing the SM effects on precipitation and evapotranspiration, the decline in 132 evapotranspiration $(-0.163 \pm 0.083 \mathrm{~mm} /$ day $)$ induced by future SM drying is roughly twice as large 133 as the SM drying effect on precipitation $(-0.097 \pm 0.052 \mathrm{~mm} /$ day) over drylands (Extended Data 
134 Fig. 5). This stronger SM limitation on evapotranspiration than on precipitation indicates that the 135 positive feedback of SM on precipitation via moisture recycling - or lower precipitation with 136 future SM decline - is partially offset by other atmospheric responses to SM, as we discuss further 137 in the following section.

\section{Mechanisms of the soil moisture impact on P-E changes}

140 Multiple theories have been postulated to explain future P-E changes over land, many of which 141 focus on thermodynamic mechanisms, including warming-driven changes in specific humidity and 142 land-ocean warming contrast ${ }^{22-24}$. Circulation changes, such as shifts in the strength of Walker and 143 Hadley circulations, are also invoked to explain deviations of P-E changes from expected 144 thermodynamic responses over land ${ }^{10-12,25-28}$, but these dynamic mechanisms are predominantly 145 driven by sea surface warming. Our finding of a strong SM effect on future P-E changes is not 146 readily explained by these mechanisms. A recent study proposed an extended thermodynamic 147 scaling of P-E changes including both local specific humidity changes and the horizontal gradient 148 of specific humidity, but this extended scaling tends to overestimate both P-E decreases in drylands and P-E increases in the wet tropics ${ }^{9}$, similar to the projected P-E changes by ocean-atmosphere

150 processes in expA (Fig. 1e). This indicates that the thermodynamic effect does not fully capture 151 the SM effect on P-E changes; rather, dynamic effects related to SM are necessary to account for 152 these changes.

154 To test this hypothesis, we explore the thermodynamic and dynamic mechanisms of P-E changes driven by long-term SM trends in GLACE-CMIP5. Relative to expA, which lacks long-term SM 156 trends, expB manifests greater temperature increases but weaker specific humidity increases (Fig. 157 2a-d). The SM effect is especially strong over drylands where negative trends in SM lead to 158 reduced evapotranspiration and evaporative cooling (Extended Data Fig. 5b), which are consistent 159 with the enhanced warming and reduced moistening in expB compared to expA (Fig. 2a-d). An 160 SM-induced horizontal gradient of specific humidity is expected to induce more moisture into 161 drylands by landward moisture flux, according to the extended thermodynamic scaling of P-E 162 changes $^{9}$. However, this negative effect may be partially or totally offset by local specific humidity 163 reductions. 

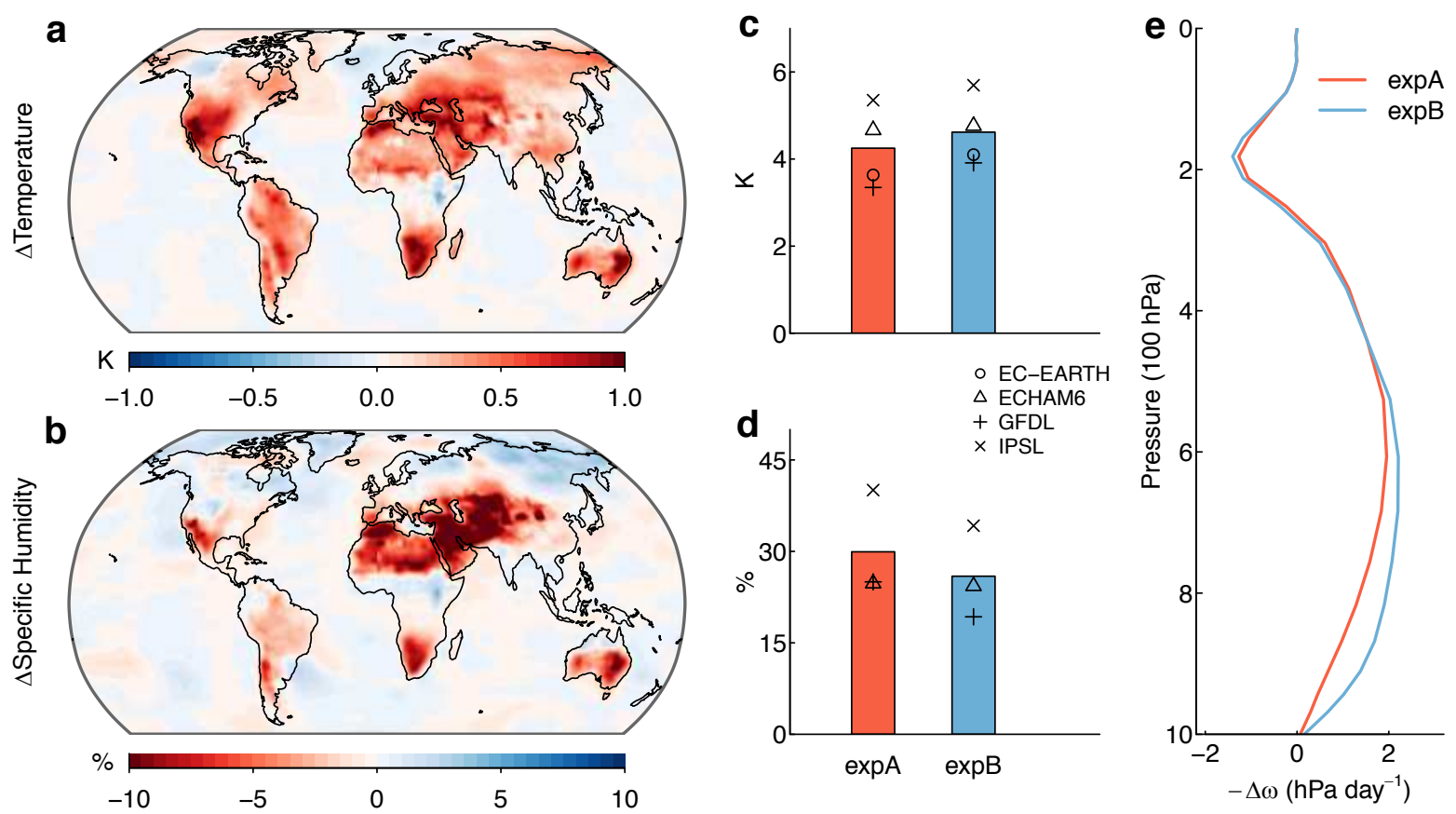

Fig. 2 | Soil moisture effects on changes in temperature, specific humidity, and vertical ascent in GLACE-CMIP5. a,b, Multi-model mean soil moisture effects (expB-expA) on projected changes $(\Delta)$ in temperature and specific humidity from historical (1971-2000) to future (20712100) periods (future minus historical values). c,d, Projected changes in temperature and specific humidity over drylands in expA and expB (bars: multi-model mean, symbols: individual models, 170 specific humidity is not available in EC-EARTH). Changes to specific humidity are expressed 171 fractionally relative to their historic period values (in percentages). e, Projected changes in 172 negative pressure velocity $(-\Delta \omega)$ over drylands in expA and $\operatorname{expB}$ for the IPSL model.

174 We examine the SM impact on atmospheric dynamic processes by comparing future changes in 175 the vertical profile of vertical motion (here quantified in terms of $-\omega$, the negative pressure velocity) 176 over drylands between expA and expB in the IPSL model. Both simulations project enhanced 177 ascent throughout the lower troposphere over drylands in the future, which is of greater magnitude 178 in expB compared to expA (Fig. 2e). In particular, the SM effect on future P-E changes is largely 179 consistent with that on tropospheric vertical ascent, with spatial correlation coefficients ranging 180 from 0.37 to 0.59 over drylands (Extended Data Fig. 6). In each season, the spatial pattern of the 181 SM effect on vertical ascent is also positively correlated with that on future P-E changes over 182 drylands, especially in summer (wet season) (Extended Data Fig. 7). Although the SM effects on 
vertical ascent and P-E vary seasonally/geographically and across models, the IPSL results support the notion that reduced SM may promote atmospheric vertical ascent, potentially contributing to the negative SM effect on P-E.

\section{Thermodynamic vs dynamic effects in the SM-(P-E) feedback}

To further compare the thermodynamic and dynamic mechanisms of the negative SM-(P-E) feedback, we analyze the SM impact on the atmospheric moisture budget from the observationally constrained MERRA-2 and ERA5 reanalysis products. We apply a statistical framework to identify the SM feedback on P-E at the monthly scale, and to isolate the SM effects on the thermodynamic and dynamic components of P-E variations. We establish a multiple linear regression model to determine the sign and strength of the SM-(P-E) feedback, which is represented by a sensitivity coefficient that measures the partial derivative of standardized P-E variations to standardized SM variations in the previous month (Methods). A sensitivity coefficient of 0.1 indicates that P-E increases by $10 \%$ of its standard deviation when previous-month SM increases by one standard deviation.

Consistent with the experimental results in Fig. 1, we find widespread negative sensitivity coefficients for $\mathrm{SM} \rightarrow(\mathrm{P}-\mathrm{E})$, i.e., the effect of $\mathrm{SM}$ on P-E, in the fully coupled simulations of GLACE-CMIP5 models and reanalysis products, with significant effects in the subtropical and mid-latitude dry regions (Fig. 3a,d,g). We further compare $\mathrm{SM} \rightarrow \mathrm{E}$ and $\mathrm{SM} \rightarrow \mathrm{P}$. As expected, SM exerts a strong positive impact on evapotranspiration, while its effect on precipitation is much weaker (Fig. 3b,c,e,f,h,i), because precipitation is strongly controlled by large-scale atmospheric dynamics. We note that the strengths of $\mathrm{SM} \rightarrow \mathrm{E}$ and $\mathrm{SM} \rightarrow \mathrm{P}$ vary across models and reanalysis products (Fig. 3c,f,i). In addition to intrinsic differences in the representation of land-atmosphere processes, different treatments of vegetation dynamics and our use of different soil depths across models/products may also contribute to uncertainties in the feedback strengths (Methods). Besides evapotranspiration, atmospheric moisture convergence (MC) is the other source of moisture for precipitation. We find consistent negative $\mathrm{SM} \rightarrow \mathrm{MC}$ in MERRA-2 and ERA5 (Fig. 3j,m). As monthly SM variations strongly and positively force evapotranspiration but generally negatively affect moisture convergence, SM has a more muted effect on precipitation than on evapotranspiration, resulting in a negative SM-(P-E) feedback. 

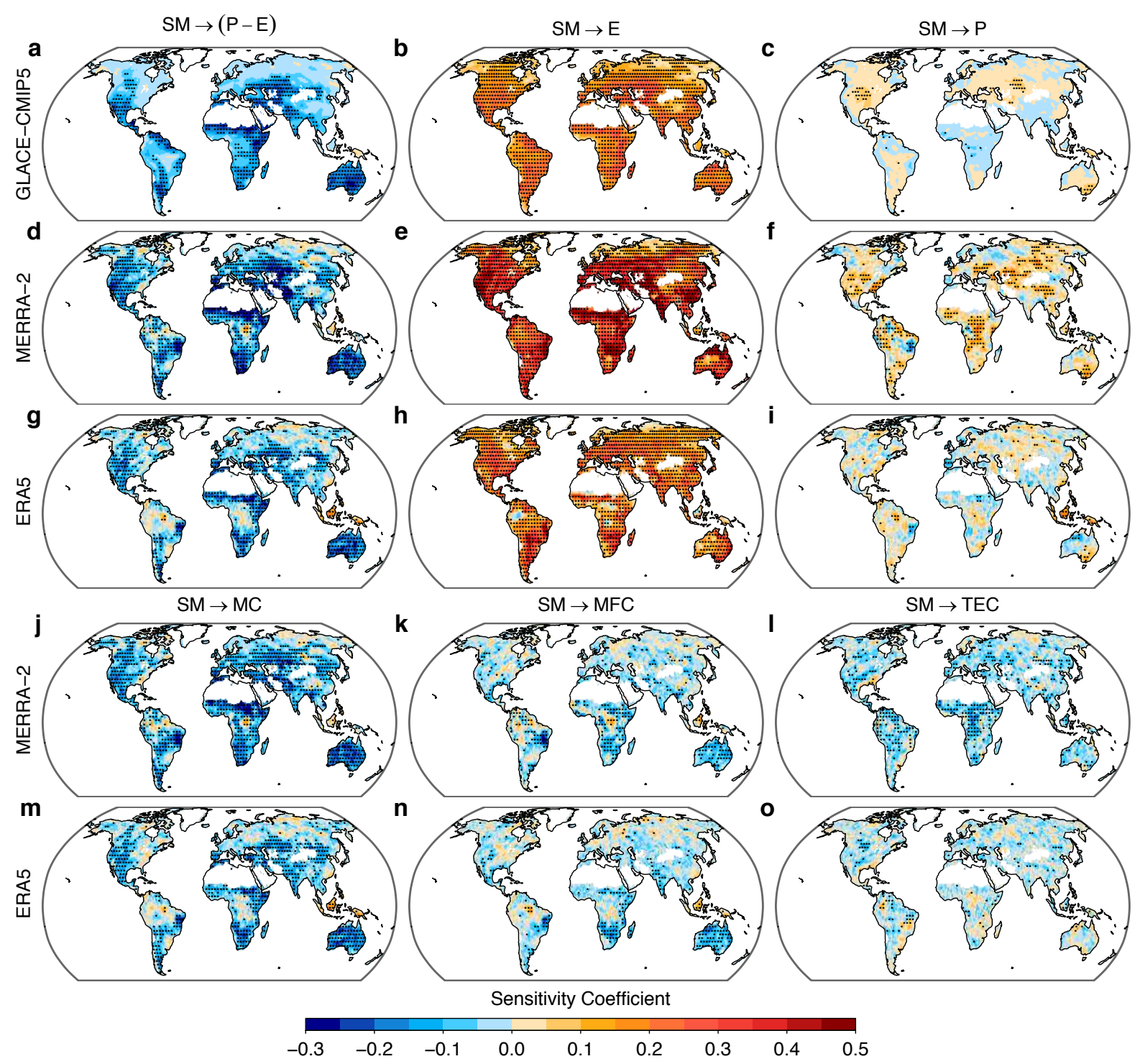

215 Fig. 3 | Soil moisture feedbacks on water availability in GLACE-CMIP5 models and

216 reanalysis datasets. a-f, Sensitivity coefficients for soil moisture $(\mathrm{SM}) \rightarrow$ precipitation minus

217 evapotranspiration (P-E), $\mathrm{SM} \rightarrow$ evapotranspiration (E), and $\mathrm{SM} \rightarrow$ precipitation (P) identified

218 based on REF of the four GLACE-CMIP5 models (1971-2100) (a-c), MERRA-2 (1980-2018) (d-

219 f), and ERA5 (1979-2018) (g-i). Mean values of the sensitivity coefficients produced by the four

220 models are shown in $\mathbf{a}-\mathbf{c}$. $\mathbf{j}-\mathbf{o}$, the same as $\mathbf{d}-\mathbf{i}$, but for $\mathrm{SM} \rightarrow$ moisture convergence (MC) (j,m),

$221 \mathrm{SM} \rightarrow$ mean flow convergence (MFC) $(\mathbf{k}, \mathbf{n})$, and $\mathrm{SM} \rightarrow$ transient eddy convergence (TEC) $(\mathbf{l}, \mathbf{0})$.

222 The sensitivity coefficient for $\mathrm{X} \rightarrow \mathrm{Y}$ denotes the partial derivative of standardized $\mathrm{Y}$ to

223 standardized $\mathrm{X}$ in the previous month, where the seasonal cycles and long-term trends in $\mathrm{X}$ and $\mathrm{Y}$

224 are removed. Stippling denotes regions where the sensitivity coefficient is significant at the $95 \%$ 
225 level according to a bootstrap test. In a-c, stippling denotes regions where the sensitivity 226 coefficient is significant at the $95 \%$ level and the sign of the sensitivity coefficient is consistent 227 with the sign of multi-model means (as shown in the figure) in at least three of the four GLACE228 CMIP5 models.

230 Although atmospheric moisture storage changes on monthly scales, the change is relatively small; 231 thus monthly P-E approximately balances moisture convergence. The latter is calculated as the 232 negative divergence $(\nabla)$ of vertically mass-integrated moisture flux from the top of the atmosphere $233(p=0)$ to the surface $\left(p=p_{s}\right)$, i.e.,

$$
P-E \approx-\frac{1}{\rho_{w} g} \nabla \cdot \int_{0}^{p_{s}}\left(\overline{\boldsymbol{u}} \bar{q}+\overline{\boldsymbol{u}^{\prime} q^{\prime}}\right) d p
$$

235

where $\rho_{w}$ is the density of water, $g$ is the acceleration due to gravity, $\boldsymbol{u}$ is the horizontal vector wind, and $q$ is specific humidity. Moisture convergence on the right side of equation (1) is decomposed into mean flow convergence determined by monthly mean wind $(\overline{\boldsymbol{u}})$ and moisture $(\bar{q})$ fields, and transient eddy convergence associated with highly variable wind $\left(\boldsymbol{u}^{\prime}\right)$ and moisture $\left(q^{\prime}\right)$ fields within storm systems ${ }^{29,30}$. We find negative SM effects on mean flow convergence and transient eddy convergence across $60-73 \%$ of the assessed land area, contributing to the negative $\mathrm{SM} \rightarrow \mathrm{MC}$ over more than $75 \%$ of the land area (Fig. $3 \mathrm{j}-\mathrm{o}$ ). As moisture flux by transient eddies is approximately diffusive ${ }^{31}$, a negative SM influence on the transient eddy convergence may be expected based on horizontal diffusion of water vapor along specific humidity gradient into a dry air column above dry soils, but could also arise from atmospheric circulation responses.

To understand how changing SM impacts mean flow convergence, we decompose monthly variations of this quantity into a thermodynamic component induced by moisture changes $(\overline{\boldsymbol{u}} \delta \bar{q})$, a mean circulation dynamic component induced by wind changes $(\bar{q} \delta \overline{\boldsymbol{u}})$, and a covariation component by the product of monthly mean moisture and wind changes $(\delta \overline{\boldsymbol{u}} \delta \bar{q})^{30}$. The negative SM feedback on mean flow convergence arises principally from the dynamic component (Fig. $4 \mathrm{a}, \mathrm{f})$ : reduced SM enhances surface heating, thereby promoting vertical ascent and associated lowlevel flow convergence, particularly in dry regions (see $\mathrm{SM} \rightarrow$ negative pressure velocity in Fig. $4 \mathrm{~d}, \mathrm{i})$. The dynamic component is negative across most land regions. In contrast, the SM effect on the thermodynamic component largely depends on the mean flow environment. Increasing SM 
255 increases atmospheric humidity, thus inducing greater moisture convergence (divergence) by the 256 thermodynamic effect when the mean low-level flow is convergent (divergent) (Fig. 4b,g,e,j). This 257 explains why the thermodynamic component of mean flow convergence acts as a positive feedback 258 in tropical convergence zones but as a negative feedback where the mean flow is divergent. The 259 covariation component is weaker and more spatially variable (Fig. 4c,h). Moreover, using an 260 attribution method based on variance decomposition (Methods), we find monthly moisture 261 convergence variations are again dominated by the dynamic component, while the contributions 262 from other components are relatively small (Extended Data Fig. 8). These results indicate that the 263 negative SM effect on moisture convergence and P-E are mainly determined by the SM regulation 264 of atmospheric circulation.

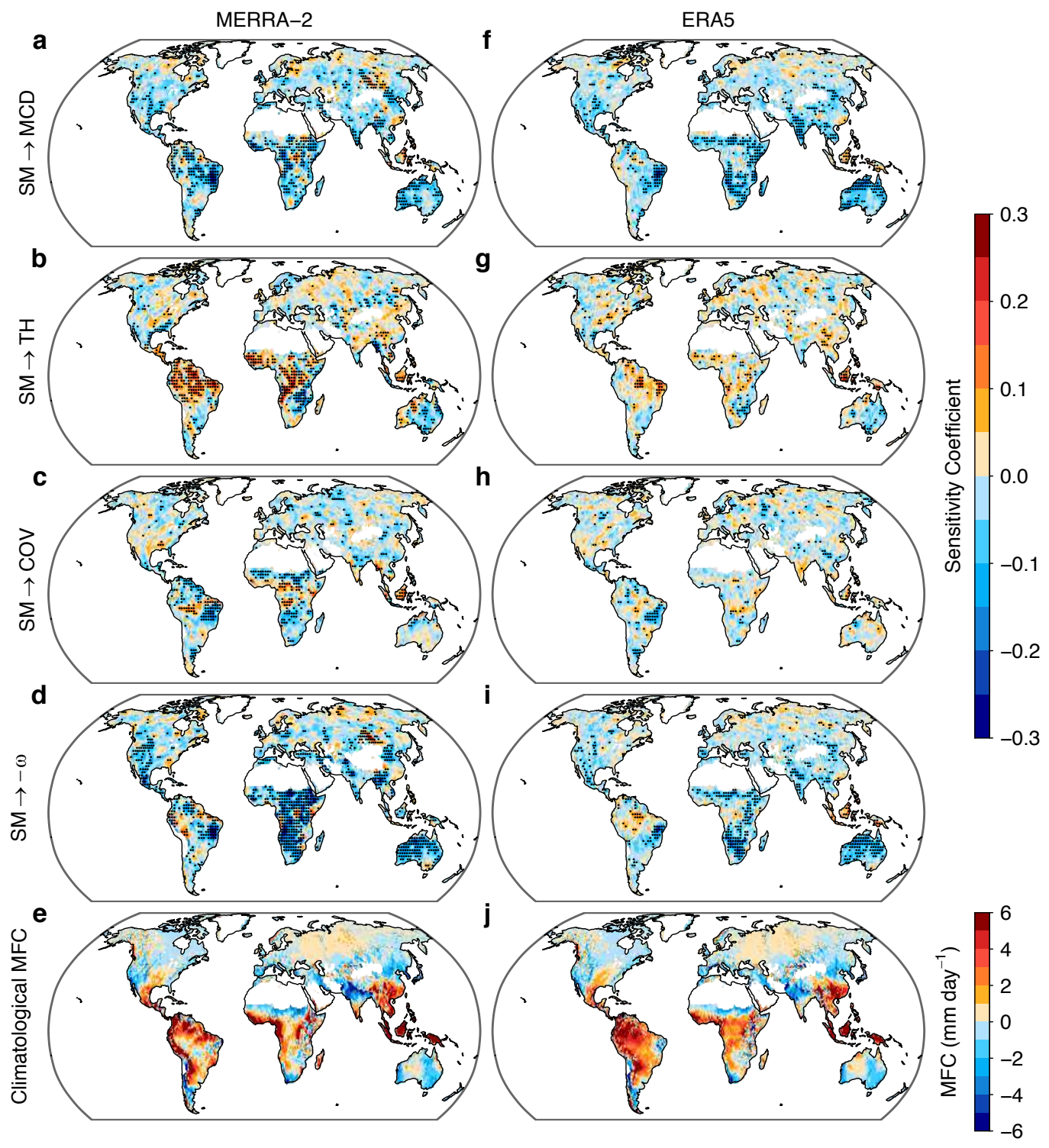


Fig. 4 | Soil moisture effects on the three components of mean flow convergence. a-e,

267 Sensitivity coefficients for soil moisture (SM) $\rightarrow$ mean circulation dynamic component (MCD) (a),

$268 \mathrm{SM} \rightarrow$ thermodynamic component (TH) (b), SM $\rightarrow$ covariation component (COV) (c), $269 \mathrm{SM} \rightarrow$ negative pressure velocity $(-\omega)$ at $700 \mathrm{hPa}$ (middle troposphere) (d), and climatological 270 monthly mean flow convergence (MFC) (e) in MERRA-2 (1980-2018). f-j, the same as a-e, but 271 for ERA5 (1979-2018). The sensitivity coefficient for $\mathrm{X} \rightarrow \mathrm{Y}$ denotes the partial derivative of 272 standardized $\mathrm{Y}$ to standardized $\mathrm{X}$ in the previous month, where the seasonal cycles and long-term 273 trends in $\mathrm{X}$ and $\mathrm{Y}$ are removed. Stippling in a-d and $\mathbf{f - i}$ denotes regions where the sensitivity 274 coefficient is significant at the $95 \%$ level according to a bootstrap test.

275

\section{Discussion and implications}

277 We demonstrate that long-term SM trends strongly influence future P-E changes, particularly over 278 drylands. Projected reductions in dryland SM directly limit evapotranspiration and reduce moisture 279 recycling for precipitation, but reduced SM also enhances moisture convergence, which partly 280 counteracts precipitation declines driven by reduced evapotranspiration. These processes result in 281 a weaker SM limitation on precipitation than on evapotranspiration, and a robust negative SM-(P282 E) feedback at monthly and climatological scales. Without feedbacks from declining SM, future 283 P-E changes would agree with the DDWW response to global warming over $31 \%$ of the land 284 regions (Fig. 1 and Extended Data Fig. 2). However, the negative SM feedback on P-E partially 285 offsets declines in P-E via non-SM factors over drylands, while slightly attenuating P-E increases 286 experienced over many non-drylands, resulting in only $19 \%$ of the land regions showing the 287 DDWW pattern.

To interpret future P-E changes over land, recent studies have emphasized the importance of landocean warming contrast ${ }^{9,22,24}$, which affects the spatial pattern of atmospheric moisture content and P-E responses, in addition to local warming-driven P-E changes. The projected decline in

292 dryland SM enhances the land-ocean warming contrast through enhanced land region warming, 293 but thermodynamic mechanisms alone cannot well explain the negative SM feedback on P-E. 294 Rather, we demonstrate that the negative SM-(P-E) feedback occurs mainly through SM induced 295 changes in evapotranspiration as well as changes to the surface energy balance that modify the 296 mean circulation, as declining SM enhances low-level vertical ascent and moisture convergence 
via associated low-level flow convergence. This dynamic effect may also be tied to declining SM reducing evapotranspiration and supporting a larger land-ocean warming contrast, which strengthens the landward pressure gradient and drives greater low-level moisture transport from the ocean to land $\mathrm{d}^{32-34}$.

The negative SM feedback on P-E has important implications for hydroclimatic variability ${ }^{35}$. From our analysis of GLACE-CMIP5 simulations, the magnitudes and frequencies of both extreme high and extreme low P-E are enhanced in the expA simulations relative to the REF (Extended Data Fig. 9). The expA simulations only include non-SM effects of oceanic and atmospheric processes, while in REF, SM variations have a positive effect on evapotranspiration but a negative feedback on moisture convergence: thus, hydroclimatic variability is muted when SM feedbacks operate. Of course, while the negative SM feedback on P-E reduces the magnitudes and frequencies of extreme P-E events in drylands, extreme hydroclimatic events, such as droughts and floods, are still projected to increase in some regions due to warming-driven ocean-atmosphere processes ${ }^{36,37}$.

Our study highlights the importance of soil moisture changes and the associated soil moistureatmosphere feedbacks in future projections of surface water availability. Although fully coupled general circulation models do include the negative soil moisture feedback on surface water availability over drylands, the feedback strength, as well as the soil moisture projections themselves, are highly variable and model dependent (Extended Data Fig. 3), leading to large uncertainty in how changes in soil moisture will affect future surface water availability (Fig. 1). In particular, we find that soil moisture variations contribute a larger proportion than other oceanic and atmospheric drivers ( 0.060 versus $0.046 \mathrm{~mm} /$ day, s.d. in Fig. $1 \mathrm{~h})$ to cross-model variations in the projected changes in dryland water availability. This points to the need for improved modelling of soil moisture trends and variability, which may be achieved through refined representation of land-atmosphere processes in general circulation models, especially the coupling between soil moisture, evapotranspiration, atmospheric circulation, and the hydrological cycle. Accurate model representation of soil moisture and the associated soil moisture-atmosphere feedbacks is crucial for providing reliable projections of surface water availability for better water resources management, and for mitigating future challenges of increasing water scarcity over drylands. 


\section{References:}

329 1. Oki, T. \& Kanae, S. Global Hydrological Cycles and World Water Resources. Science 313, 1068-1072 (2006).

2. Rockström, J. et al. Future water availability for global food production: The potential of

332 green water for increasing resilience to global change. Water Resources Research (2018) doi:10.1029/2007WR006767@10.1002/(ISSN)1944-7973.LANDUSE1.

3. Anderegg, W. R. L. et al. Tree mortality predicted from drought-induced vascular damage.

$335 \quad$ Nature Geosci 8, 367-371 (2015).

4. Ruppert, J. C. et al. Quantifying drylands' drought resistance and recovery: the importance of

337 drought intensity, dominant life history and grazing regime. Glob Change Biol 21, 1258-1270 338 (2015).

5. Huntington, T. G. Evidence for intensification of the global water cycle: Review and synthesis. Journal of Hydrology 319, 83-95 (2006).

6. Held, I. M. \& Soden, B. J. Robust Responses of the Hydrological Cycle to Global Warming. J. Climate 19, 5686-5699 (2006).

7. Lorenz, D. J. \& DeWeaver, E. T. The Response of the Extratropical Hydrological Cycle to 344 Global Warming. J. Climate 20, 3470-3484 (2007).

345 8. Greve, P. \& Seneviratne, S. I. Assessment of future changes in water availability and aridity. 346 Geophysical Research Letters 42, 5493-5499 (2015).

347 9. Byrne, M. P. \& O’Gorman, P. A. The Response of Precipitation Minus Evapotranspiration to 348 Climate Warming: Why the "Wet-Get-Wetter, Dry-Get-Drier" Scaling Does Not Hold over 349 Land. J. Climate 28, 8078-8092 (2015).

350 10. Chou, C., Neelin, J. D., Chen, C.-A. \& Tu, J.-Y. Evaluating the "Rich-Get-Richer" 351 Mechanism in Tropical Precipitation Change under Global Warming. J. Climate 22, 19823522005 (2009).

353 11. Vecchi, G. A. et al. Weakening of tropical Pacific atmospheric circulation due to 354 anthropogenic forcing. Nature 441, 73-76 (2006).

355 12. Chadwick, R., Boutle, I. \& Martin, G. Spatial Patterns of Precipitation Change in CMIP5: 356 Why the Rich Do Not Get Richer in the Tropics. J. Climate 26, 3803-3822 (2012). 
357 13. Guillod, B. P., Orlowsky, B., Miralles, D. G., Teuling, A. J. \& Seneviratne, S. I.

358 Reconciling spatial and temporal soil moisture effects on afternoon rainfall. Nature

359 Communications 6, 6443 (2015).

360 14. Seneviratne, S. I. et al. Investigating soil moisture-climate interactions in a changing 361 climate: A review. Earth-Science Reviews 99, 125-161 (2010).

362 15. Taylor, C. M., Parker, D. J. \& Harris, P. P. An observational case study of mesoscale 363 atmospheric circulations induced by soil moisture. Geophysical Research Letters 34, (2007).

364 16. Ookouchi, Y., Segal, M., Kessler, R. C. \& Pielke, R. A. Evaluation of Soil Moisture 365 Effects on the Generation and Modification of Mesoscale Circulations. Mon. Wea. Rev. 112, 366 2281-2292 (1984).

367 17. Segal, M. \& Arritt, R. w. Nonclassical Mesoscale Circulations Caused by Surface

368 Sensible Heat-Flux Gradients. Bull. Amer. Meteor. Soc. 73, 1593-1604 (1992).

369 18. Taylor, C. M., de Jeu, R. A. M., Guichard, F., Harris, P. P. \& Dorigo, W. A. Afternoon 370 rain more likely over drier soils. Nature 489, 423-426 (2012).

371 19. Hsu, H., Lo, M.-H., Guillod, B. P., Miralles, D. G. \& Kumar, S. Relation between

372 precipitation location and antecedent/subsequent soil moisture spatial patterns: Precipitation-

373 Soil Moisture Coupling. J. Geophys. Res. Atmos. 122, 6319-6328 (2017).

374 20. Froidevaux, P., Schlemmer, L., Schmidli, J., Langhans, W. \& Schär, C. Influence of the 375 Background Wind on the Local Soil Moisture-Precipitation Feedback. J. Atmos. Sci. 71, 782376799 (2013).

377 21. Seneviratne, S. I. et al. Impact of soil moisture-climate feedbacks on CMIP5 projections: 378 First results from the GLACE-CMIP5 experiment. Geophysical Research Letters 40, 5212$379 \quad 5217(2013)$.

380 22. Byrne, M. P. \& O'Gorman, P. A. Land-Ocean Warming Contrast over a Wide Range of 381 Climates: Convective Quasi-Equilibrium Theory and Idealized Simulations. J. Climate 26, 382 4000-4016 (2012).

383 23. Joshi, M. M., Gregory, J. M., Webb, M. J., Sexton, D. M. H. \& Johns, T. C. Mechanisms 384 for the land/sea warming contrast exhibited by simulations of climate change. Clim Dyn 30, 385 455-465 (2008).

386 24. Fasullo, J. T. Robust Land-Ocean Contrasts in Energy and Water Cycle Feedbacks. $J$. 387 Climate 23, 4677-4693 (2010). 
25. Tokinaga, H., Xie, S.-P., Deser, C., Kosaka, Y. \& Okumura, Y. M. Slowdown of the

Walker circulation driven by tropical Indo-Pacific warming. Nature 491, 439-443 (2012).

26. Lu, J., Vecchi, G. A. \& Reichler, T. Expansion of the Hadley cell under global warming.

Geophysical Research Letters 34, (2007).

392 27. Karnauskas, K. B. \& Ummenhofer, C. C. On the dynamics of the Hadley circulation and 393 subtropical drying. Clim Dyn 42, 2259-2269 (2014).

394 28. Lau, W. K. M. \& Kim, K.-M. Robust Hadley Circulation changes and increasing global 395 dryness due to $\mathrm{CO}_{2}$ warming from CMIP5 model projections. Proc Natl Acad Sci USA 112, $396 \quad 3630-3635(2015)$.

397 29. Seager, R. et al. Model Projections of an Imminent Transition to a More Arid Climate in 398 Southwestern North America. Science 316, 1181-1184 (2007).

399 30. Seager, R., Naik, N. \& Vecchi, G. A. Thermodynamic and Dynamic Mechanisms for 400 Large-Scale Changes in the Hydrological Cycle in Response to Global Warming. J. Climate $40123,4651-4668(2010)$.

402 31. O'Gorman, P. A. \& Schneider, T. Stochastic Models for the Kinematics of Moisture 403 Transport and Condensation in Homogeneous Turbulent Flows. J. Atmos. Sci. 63, 2992-3005 404 (2006).

405 32. He, J. \& Soden, B. J. A re-examination of the projected subtropical precipitation decline. $406 \quad$ Nature Climate Change 7, 53-57 (2017).

407 33. Chadwick, R., Ackerley, D., Ogura, T. \& Dommenget, D. Separating the Influences of 408 Land Warming, the Direct CO2 Effect, the Plant Physiological Effect, and SST Warming on 409 Regional Precipitation Changes. Journal of Geophysical Research: Atmospheres 124, 624410640 (2019).

411 34. Findell, K. L. et al. Rising Temperatures Increase Importance of Oceanic Evaporation as 412 a Source for Continental Precipitation. Journal of Climate 32, 7713-7726 (2019).

413 35. Krakauer, N. Y., Cook, B. I. \& Puma, M. J. Contribution of soil moisture feedback to 414 hydroclimatic variability. Hydrol. Earth Syst. Sci. 16 (2010).

415 36. Roudier, P. et al. Projections of future floods and hydrological droughts in Europe under $416 \mathrm{a}+2^{\circ} \mathrm{C}$ global warming. Climatic Change 135, 341-355 (2016). 
37. Zhou, S., Zhang, Y., Williams, A. P. \& Gentine, P. Projected increases in intensity, frequency, and terrestrial carbon costs of compound drought and aridity events. Science Advances 5, eaau5740 (2019).

\section{Materials and Methods}

CMIP5 model simulations. We used 35 CMIP5 models (listed in Table S1) covering the historical (1971-2000) and future (2071-2100, RCP8.5 high emissions scenario) periods. The ensemble member "rli1pi" was used for each model. These models were selected because they provide the monthly total soil moisture content, precipitation, and latent heat flux required for our analyses. Evapotranspiration was calculated from latent heat flux in each model. We calculated multi-model mean annual changes in these variables between the historical and future periods.

GLACE-CMIP5 experiments. We used simulations from four models (i.e., EC-EARTH, ECHAM6, GFDL and IPSL) that participate in the GLACE-CMIP5 experiment, which was performed to assess the impact of SM-climate feedbacks in CMIP5 projections ${ }^{21}$ and has been widely used to isolate the SM effect on the atmosphere ${ }^{38-40}$. We did not use the other two models (ACCESS and CCSM4) in the GLACE-CMIP5 experiment because of problems with the prescribed SM. In each model, we used three simulations, i.e., a reference simulation (REF) and two perturbation simulations (expB and expA), covering the period from 1950 to 2100 . All three simulations were driven by prescribed sea surface temperature, sea ice, land use, and $\mathrm{CO}_{2}$ concentrations from the respective CMIP5 simulations (the historical simulations over 1950-2005 and the RCP8.5 scenario over 2006-2100). The difference between the three simulations is that SM was fully coupled with the atmosphere in REF, while SM climatology was prescribed as the 1971-2000 climatology (expA) and a centered, 30-year running mean climatology from REF $(\operatorname{expB})$ in the two perturbation simulations (Extended Data Fig. 1). Comparing simulated atmospheric variables between the three simulations, we could isolate the effects of SM trends

443 (expB-expA) and variability (REF-expB) and total SM effect (REF-expA) due to SM-atmosphere 444 feedbacks.

446 For our analyses, we used monthly total soil moisture content, precipitation, and latent heat flux 447 from the three simulations in each model. Evapotranspiration was calculated from latent heat flux 
448 in each simulation. Multi-model mean annual changes in SM between the historical and future 449 periods in REF were compared with those from CMIP5. In each model, we calculated mean annual 450 changes in precipitation, evapotranspiration, and P-E between the historical and future periods in 451 the three simulations. We isolated the contributions of total SM changes (REF-expA), SM trends 452 (expB-expA), and SM variability (REF-expB) to future changes in these variables. To investigate 453 the mechanisms behind the SM effect on P-E changes, we used near-surface $(2 \mathrm{~m})$ temperature, 454 specific humidity, and the vertical profile of pressure velocity from expA and expB. Temperature 455 is available in all four models, but specific humidity is not archived in EC-EARTH, and pressure 456 velocity is only available in IPSL.

Reanalysis datasets. To identify the SM feedback on P-E, we used monthly root-zone SM, 459 precipitation, evapotranspiration from the Modern-Era Retrospective analysis for Research and Applications, version 2 (MERRA-2) ${ }^{41}$ dataset (1980-2018), and the European Centre for Medium-

461 Range Weather Forecasts (ERA5, 1979-2018). In ERA5, we used 0-100cm SM to approximate 462 root-zone SM. As the two reanalysis datasets are constrained by in situ and satellite remote sensing observations, they largely reflect the relationship between SM and P-E. However, these reanalysis 464 datasets prescribe monthly climatology of leaf area index based on satellite products. Because 465 vegetation dynamics generally amplify SM-driven evapotranspiration and precipitation anomalies 467 reanalysis products.

To further understand how SM impacts P-E, we used vertically integrated moisture convergence

470 (MC) and decomposed MC into mean flow convergence and transient eddy convergence, using 471 monthly specific humidity and eastward and northward wind at all pressure levels $(0-1000 \mathrm{hPa})$, 472 and surface pressure from ERA5 and MERRA2 (see "Moisture Convergence Decomposition" 473 below). We also used monthly pressure velocity at $700 \mathrm{hPa}$, which provides a good representation 474 of the middle tropospheric circulation, from ERA5 and MERRA2 to assess the SM effect on 475 atmospheric vertical motion.

477 Definition of drylands. Drylands are generally defined as regions with an aridity index (the ratio 478 of precipitation to potential evapotranspiration, $\mathrm{P} / \mathrm{E}_{0}$ ) less than $0.65^{43}$. There are numerous ways 
479 to estimate $\mathrm{E}_{0}$ under certain climatic conditions ${ }^{44}$, which may result in varying definitions of 480 drylands. A good $\mathrm{E}_{0}$ estimation can well predict mean annual evapotranspiration (E) through the 481 Budyko functions ${ }^{45}$. A widely used analytical Budyko function ${ }^{46}$ is

$$
\frac{E}{P}=\frac{1}{\left[\left(\frac{E_{0}}{P}\right)^{-n}+1\right]^{\frac{1}{n}}}
$$

483 The parameter $n$ represents the influence of land characteristics on E. Comparing existing Budyko 484 functions, the Pike's equation $(n=2.0)$ is closest to the original Budyko curve ${ }^{45}$. Using the Pike's 485 equation to describe the relationship between $\mathrm{E} / \mathrm{P}$ and $\mathrm{E}_{0} / \mathrm{P}$, we obtained a $\mathrm{E} / \mathrm{P}$ ratio of 0.84 when $486 \mathrm{P} / \mathrm{E}_{0}$ is set as the threshold of 0.65 . In other words, drylands are identified as regions where $\mathrm{E} / \mathrm{P}$ is 487 greater than 0.84 . Noting that climate models do not produce $\mathrm{E}_{0}$, but do simulate $\mathrm{E}$ and $\mathrm{P}$, we 488 therefore defined drylands as regions where multi-model mean E/P is larger than 0.84 in the 489 historical period (1971-2000) for CMIP5 and GLACE-CMIP5 (REF) models (Extended Data Fig. $4902 \mathrm{a}, \mathrm{c})$.

492 The SM-(P-E) feedback. Because SM and P-E are strongly coupled, it is difficult to isolate the 493 SM feedback on P-E from the direct P-E impact on SM. A feedback has been quantified based on 494 the temporally lagged correlation in many previous studies ${ }^{47,48}$. The difficulty in determining the 495 SM-(P-E) feedback is mainly because of the persistent impact of P-E (especially P) on SM, as the 496 slow processes of soil water percolation, evaporation, and transpiration lead to relatively long SM 497 memory (weeks to months) of precipitation events ${ }^{49}$. The lagged correlation between SM and 498 subsequent P-E therefore may reflect precipitation autocorrelation rather than the SM-(P-E) 499 feedback ${ }^{47}$. Additionally, the seasonal cycles and long-term trends of P-E and SM also contribute 500 to the lagged correlation ${ }^{47}$, although they are largely driven by external factors such as regional 501 climatology and global warming.

503 To address these issues, we established a multiple linear regression model between P-E and one504 month lagged SM to assess the SM-(P-E) feedback.

$$
(P-E)_{d}(t+1)=n_{0}+n_{1} \cdot S M_{d}(t)+n_{2} \cdot(P-E)_{d}(t)
$$

506 The subscript $d$ indicates that the multi-year mean seasonal cycle and the linear trend of the 507 variable have been removed, and the indicator $t$ represents monthly steps. The lagged term 
$508(P-E)_{d}(t)$ on the right side of equation (3) aims to remove the effect of P-E autocorrelation.

509 Therefore, the regression coefficient $n_{1}\left(\frac{\partial(P-E)_{d}(t+1)}{\partial S M_{d}(t)}\right)$ represents the SM feedback on P-E.

510 Although the SM-(P-E) feedback may be non-linear and time-dependent, the regression coefficient

511 obtained from the linear model reflects the long-term mean effect of SM on P-E.

513 We used partial least square regression (PLSR) ${ }^{50}$ to obtain the regression coefficient $n_{1}$ in equation

514 (3). PLSR combines features of principal component analysis and multiple linear regression

515 (MLR). It projects the predictor variables onto orthogonal principal components to overcome the

516 issue of multicollinearity among predictor variables (i.e., the predictor variables are highly linearly

517 related). PLSR then regresses the dependent variable against principal components to obtain

518 regression slopes. We find that $(P-E)_{d}(t)$ and $S M_{d}(t)$ are weakly correlated in most grid cells.

519 In these cases, PLSR obtains the same regression results as MLR. In case of a strong correlation

520 between $(P-E)_{d}(t)$ and $S M_{d}(t)$ at some grid cells, we use PLSR instead of MLR to overcome

521 the multicollinearity problem. To facilitate comparison of the SM-(P-E) feedback across different

522 regions and in different datasets/models, we used PLSR standardized coefficients (or

523 dimensionless sensitivity coefficients) corresponding to standardized $(P-E)_{d}$ and $S M_{d}$ of zero

524 mean and unit variance (z-score) to measure the SM-(P-E) feedback.

525

526 As the SM-(P-E) feedback may be impacted by natural variability, we used a bootstrap test to

527 determine the significance of the sensitivity coefficients. We performed bootstrap analyses with

528500 realizations for the two reanalysis datasets (480 months for ERA5 and 468 months for

529 MERRA-2) and 2000 realizations for fully coupled simulations of the four GLACE-CMIP5

530 models (1560 months, 1971-2100). The time series are randomly resampled to obtain the 95\%

531 confidence intervals of the sensitivity coefficients. We used the adjusted bootstrap percentile

532 interval as different types of confidence intervals generate very similar results. According to the

533 bootstrap confidence intervals, the sensitivity coefficients are deemed to be statistically significant

534 if the $95 \%$ confidence intervals do not contain zero.

536 We also used similar multiple linear regression models and bootstrap tests to assess the SM

537 feedbacks on evapotranspiration and precipitation. To demonstrate that the SM-atmosphere

538 feedbacks are consistent between current and future climates, we used data from the fully coupled 
539 GLACE-CMIP5 simulations to compare the SM-atmosphere feedbacks: (1) between recent (1979540 2018) and future (2061-2100) periods, and (2) by removing and retaining the long-term trends in

541 the variables during the 1971-2100 period. Both comparisons show consistent strong positive $542 \mathrm{SM} \rightarrow \mathrm{E}$, weak $\mathrm{SM} \rightarrow \mathrm{P}$, and negative $\mathrm{SM} \rightarrow(\mathrm{P}-\mathrm{E})$ (Fig. 3a-c and Extended Data Fig. 10). In 543 particular, the spatial correlation coefficient for $\mathrm{SM} \rightarrow(\mathrm{P}-\mathrm{E})$ is 0.92 in comparison (1) and 0.97 in 544 comparison (2), indicating that the negative SM-(P-E) feedback is robust to the presence of long545 term climate change.

547 Moisture Convergence Decomposition. Atmospheric MC is calculated as the negative 548 divergence of vertically integrated moisture flux over the pressure $(p)$ from the top of the 549 atmosphere $(p=0)$ to the surface $\left(p=p_{s}\right)$.

$$
M C=-\frac{1}{\rho_{w} g} \nabla \cdot \int_{0}^{p_{s}}(\boldsymbol{u} q) d p
$$

$551 \rho_{w}$ is the density of water, $g$ is the acceleration due to gravity, $\nabla$ is the horizontal divergence 552 operator, $\boldsymbol{u}$ is the horizontal vector wind, and $q$ is specific humidity.

554 At the monthly scale, MC can be decomposed into mean flow convergence (MFC) determined by 555 atmospheric mean wind and moisture fields and transient eddy convergence (TEC) by highly 556 variable (hourly to daily) wind and moisture fields within storm systems ${ }^{29}$.

$$
M C=-\frac{1}{\rho_{w} g} \nabla \cdot \int_{0}^{p_{s}}\left(\overline{\boldsymbol{u}} \bar{q}+\overline{\boldsymbol{u}^{\prime} q^{\prime}}\right) d p
$$

$$
M F C=-\frac{1}{\rho_{w} g} \nabla \cdot \int_{0}^{p_{s}}(\overline{\boldsymbol{u}} \bar{q}) d p
$$

$$
T E C=-\frac{1}{\rho_{w} g} \nabla \cdot \int_{0}^{p_{s}}\left(\overline{\boldsymbol{u}^{\prime} q^{\prime}}\right) d p
$$

560 Overbars indicate monthly mean values, and primes represent departures from the monthly mean 561 values.

563 Using climatological monthly values of $\overline{\boldsymbol{u}}$ and $\bar{q}$ as reference, monthly MFC anomalies $(\delta M F C)$ 564 can be further decomposed into three components $\left.{ }^{30}: 1\right)$ a thermodynamic component $(\delta T H)$ 565 induced by specific humidity anomalies, 2) a mean circulation dynamic component $(\delta M C D)$ 
566 induced by horizontal wind anomalies, and 3) a covariation component ( $\delta C O \mathrm{~V})$ induced by the 567 product of specific humidity anomalies and horizontal wind anomalies.

$$
\delta M F C=-\frac{1}{\rho_{w} g} \nabla \cdot \int_{0}^{p_{s}}\left(\overline{\boldsymbol{u}}_{0} \delta \bar{q}+\bar{q}_{0} \delta \overline{\boldsymbol{u}}+\delta \overline{\boldsymbol{u}} \delta \bar{q}\right) d p
$$

$$
\delta T H=-\frac{1}{\rho_{w} g} \nabla \cdot \int_{0}^{p_{s}}\left(\overline{\boldsymbol{u}}_{0} \delta \bar{q}\right) d p
$$

$$
\delta M C D=-\frac{1}{\rho_{w} g} \nabla \cdot \int_{0}^{p_{s}}\left(\bar{q}_{0} \delta \overline{\boldsymbol{u}}\right) d p
$$

571

$$
\delta \operatorname{COV}=-\frac{1}{\rho_{w} g} \nabla \cdot \int_{0}^{p_{s}}(\delta \overline{\boldsymbol{u}} \delta \bar{q}) d p
$$

572 The subscript 0 represents climatological monthly values and $\delta$ represents departure from the 573 monthly climatology.

574

575 Attribution analysis. We used a variance decomposition method ${ }^{51,52}$ to assess contributions of each MC component to monthly variations in MC. We removed the long-term trends and seasonal cycles to focus on the sub-seasonal and inter-annual variations in $\mathrm{MC}$.

$$
M C_{d}=M F C_{d}+T E C_{d}
$$

579 As in equation (3), the subscript $d$ indicates the variable is linearly detrended and deseasonalized. 580 The variance of $M C_{d}\left(\operatorname{var}\left(M C_{d}\right)\right)$ can be decomposed into its covariance with the two components 581 on the right side of equation (12).

$$
\operatorname{var}\left(M C_{d}\right)=\operatorname{cov}\left(M C_{d}, M F C_{d}\right)+\operatorname{cov}\left(M C_{d}, T E C_{d}\right)
$$

583 The contributions of $M F C_{d}(R(M C, M F C))$ and $T E C_{d}(R(M C, T E C))$ to $M C_{d}$ variations in 584 MERRA2 (1980-2018) and ERA5 (1979-2018) are therefore calculated as

$$
\begin{aligned}
& R(M C, M F C)=\frac{\operatorname{cov}\left(M C_{d}, M F C_{d}\right)}{\operatorname{var}\left(M C_{d}\right)} \\
& R(M C, T E C)=\frac{\operatorname{cov}\left(M C_{d}, T E C_{d}\right)}{\operatorname{var}\left(M C_{d}\right)}
\end{aligned}
$$

587 Similarly, we assessed contributions of the three components of $M F C_{d}$ to $M C_{d}$ variations. The 588 separated contributions of $M F C_{d}, T E C_{d}$ and the three components of $M F C_{d}$ to $M C_{d}$ variations are 589 shown in Extended Data Fig. 8. 
591 Data availability. The GLACE-CMIP5 simulations are available from S.I.S. 592 (sonia.seneviratne@ethz.ch) and the climate modelling groups upon reasonable request. All other 593 data used in this study are available online. The CMIP5 model simulations are from https://esgf594 node.1lnl.gov/search/cmip5/. The ERA5 reanalysis data are from 595 https://www.ecmwf.int/en/forecasts/datasets/archive-datasets/reanalysis-datasets/era5. The 596 MERRA-2 reanalysis data are from https:/gmao.gsfc.nasa.gov/reanalysis/MERRA597 2/data_access/. The source data for the figures are publicly available (https://doi.org/ 598 10.6084/m9.figshare.12982880).

600 Code availability. The code used for modelling and reanalysis data analyses is publicly available 601 (https://doi.org/10.5281/zenodo.4041736).

602

\section{References}

604 38. Lorenz, R. et al. Influence of land-atmosphere feedbacks on temperature and 605 precipitation extremes in the GLACE-CMIP5 ensemble. Journal of Geophysical Research: 606 Atmospheres 121, 607-623 (2016).

607 39. Berg, A. et al. Land-atmosphere feedbacks amplify aridity increase over land under 608 global warming. Nature Climate Change 6, 869-874 (2016).

609 40. Zhou, S. et al. Land-atmosphere feedbacks exacerbate concurrent soil drought and 610 atmospheric aridity. PNAS 201904955 (2019) doi:10.1073/pnas.1904955116.

611 41. Gelaro, R. et al. The Modern-Era Retrospective Analysis for Research and Applications, 612 Version 2 (MERRA-2). J. Climate 30, 5419-5454 (2017).

613 42. Green, J. K. et al. Regionally strong feedbacks between the atmosphere and terrestrial 614 biosphere. Nature Geoscience 10, 410-414 (2017).

615 43. Huang, J., Yu, H., Guan, X., Wang, G. \& Guo, R. Accelerated dryland expansion under 616 climate change. Nature Climate Change 6, 166-171 (2016).

617 44. Milly, P. C. D. \& Dunne, K. A. Potential evapotranspiration and continental drying. $618 \quad$ Nature Climate Change 6, 946-949 (2016).

619 45. Zhou, S., Yu, B., Huang, Y. \& Wang, G. The complementary relationship and generation 620 of the Budyko functions. Geophysical Research Letters 42, 1781-1790 (2015). 
621 46. Choudhury, BhaskarJ. Evaluation of an empirical equation for annual evaporation using 622 field observations and results from a biophysical model. Journal of Hydrology 216, 99-110 623 (1999).

624 47. Wei, J., Dickinson, R. E. \& Chen, H. A Negative Soil Moisture-Precipitation

625 Relationship and Its Causes. J. Hydrometeor. 9, 1364-1376 (2008).

626 48. Zhang, J., Wang, W.-C. \& Wei, J. Assessing land-atmosphere coupling using soil

627 moisture from the Global Land Data Assimilation System and observational precipitation. $J$.

628 Geophys. Res. 113, D17119 (2008).

629 49. Seneviratne, S. I. et al. Soil Moisture Memory in AGCM Simulations: Analysis of Global 630 Land-Atmosphere Coupling Experiment (GLACE) Data. J. Hydrometeor. 7, 1090-1112 631 (2006).

632 50. Geladi, P. \& Kowalski, B. R. Partial least-squares regression: a tutorial. Analytica 633 Chimica Acta 185, 1-17 (1986).

634 51. Zhou, S. et al. Sources of Uncertainty in Modeled Land Carbon Storage within and 635 across Three MIPs: Diagnosis with Three New Techniques. J. Climate 31, 2833-2851 (2018).

636 52. Zhou, S. et al. Response of Water Use Efficiency to Global Environmental Change Based 637 on Output From Terrestrial Biosphere Models: Drivers of WUE Variability. Global

638 Biogeochemical Cycles 31, 1639-1655 (2017).

639

640 Correspondence Statement

641 Correspondence and requests for materials should be addressed to S.Z..

\section{Acknowledgements}

644 We acknowledge the World Climate Research Programme's Working Group on Coupled 645 Modelling, which is responsible for CMIP, and we thank the climate modeling groups (listed in 646 Table S1 of this paper) for producing and making available their model output. For CMIP the U.S. 647 Department of Energy's Program for Climate Model Diagnosis and Intercomparison provides 648 coordinating support and led development of software infrastructure in partnership with the Global 649 Organization for Earth System Science Portals. S.Z. acknowledges support from the Lamont- 
650 Doherty Postdoctoral Fellowship and the Earth Institute Postdoctoral Fellowship. P.G. 651 acknowledges support from NASA ROSES Terrestrial hydrology (NNH17ZDA00IN-THP) and 652 NOAA MAPP NA17OAR4310127. A.P.W. and B.I.C. acknowledge support from the NASA 653 Modeling, Analysis, and Prediction (MAP) program (NASA 80NSSC17K0265). T.F.K. 654 acknowledges support from the RUBISCO SFA, which is sponsored by the Regional and Global 655 Model Analysis (RGMA) Program in the Climate and Environmental Sciences Division (CESD) 656 of the Office of Biological and Environmental Research (BER) in the U.S. Department of Energy 657 Office of Science, and additional support from a DOE Early Career Research Program award \#DE658 SC0021023. We also acknowledge Richard Seager and Jason Smerdon from Lamont-Doherty 659 Earth Observatory of Columbia University for insightful discussion and techincal assistance with 660 and interpretation of the moisture convergence decomposition (R.S.). LDEO contribution number 661 is 8453.

\section{Author contributions}

664 S.Z. conceived and designed the study. S.Z. processed model simulations and reanalysis data. S.Z., 665 A.P.W., B.R.L., A.M.B., Y.Z., T.F.K., B.I.C., S.H., S.I.S. and P.G. contributed to data analysis 666 and interpretation. S.Z. drafted the manuscript. All authors edited the manuscript.

668 Competing interests

669 The authors declare no competing interests. 


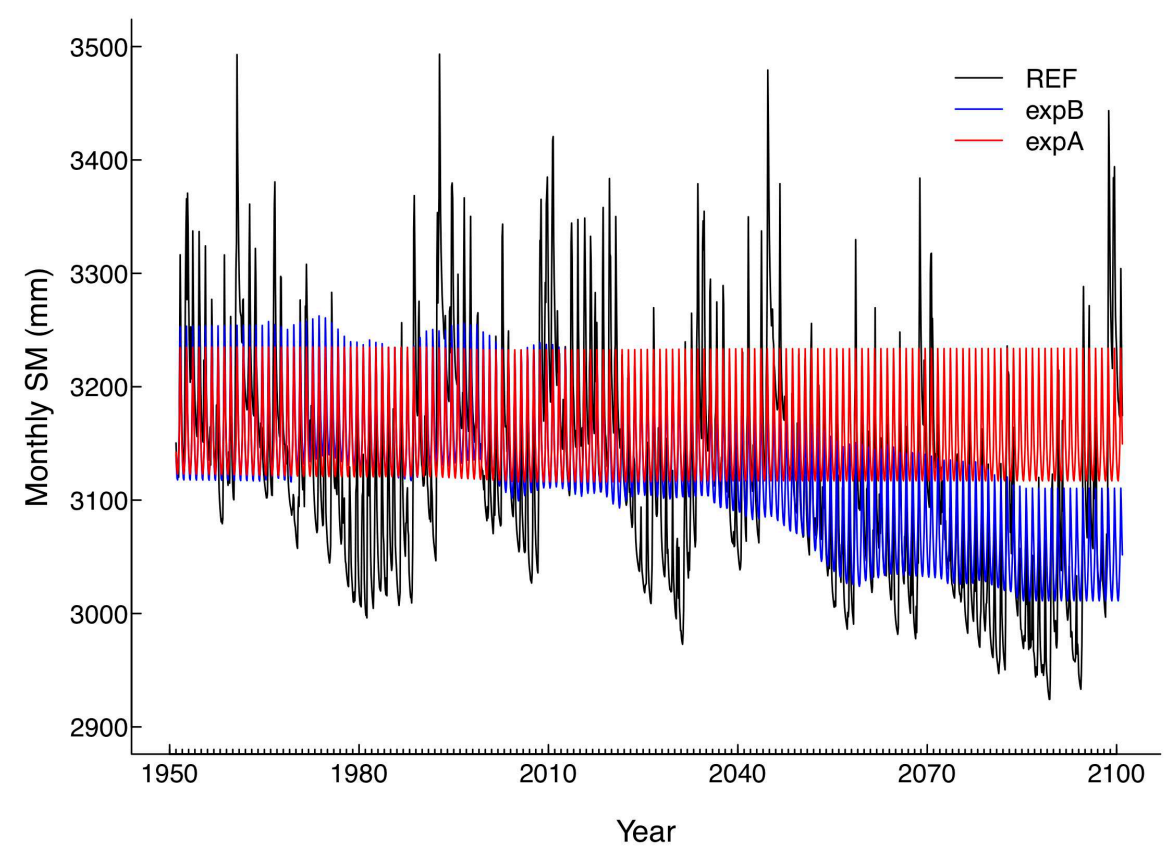

670

671 Extended Data Fig. 1 | Illustration of total column monthly soil moisture (SM) in the three

672 simulations in GLACE-CMIP5. SM data shown in the figure are obtained from a grid cell in the 673 GFDL model. 

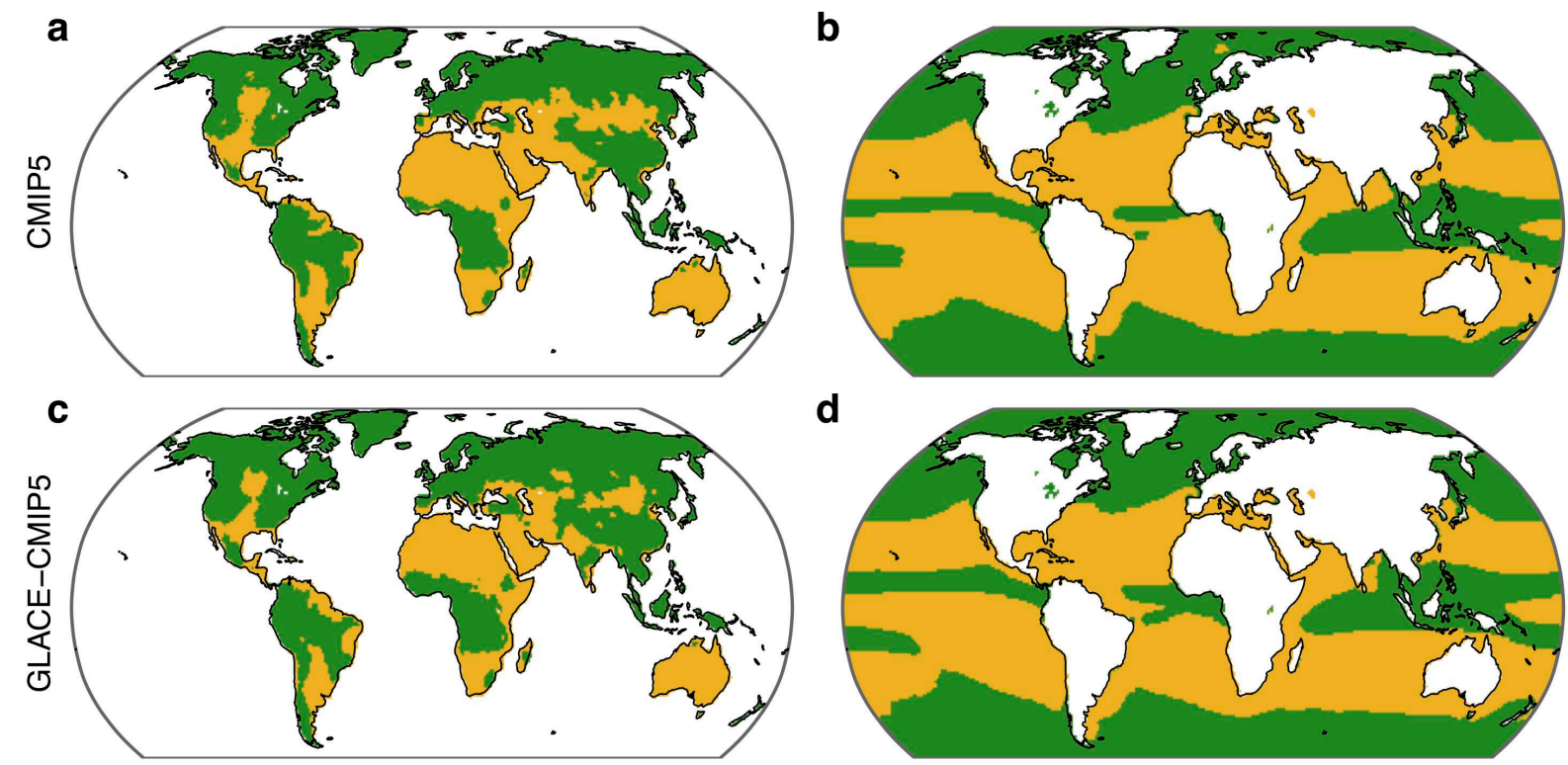

d

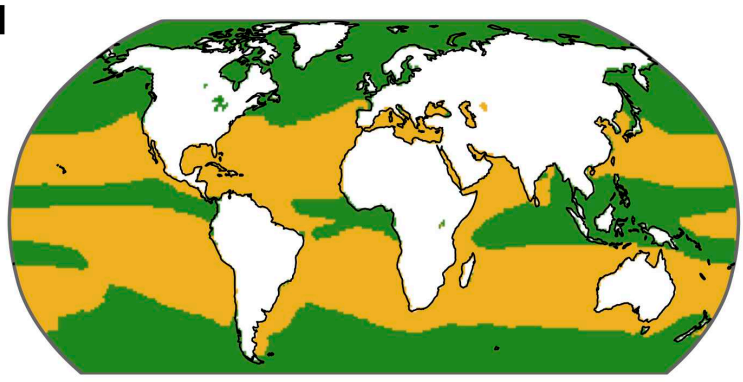

Non-Drylands/Wet ocean

Drylands/Dry ocean
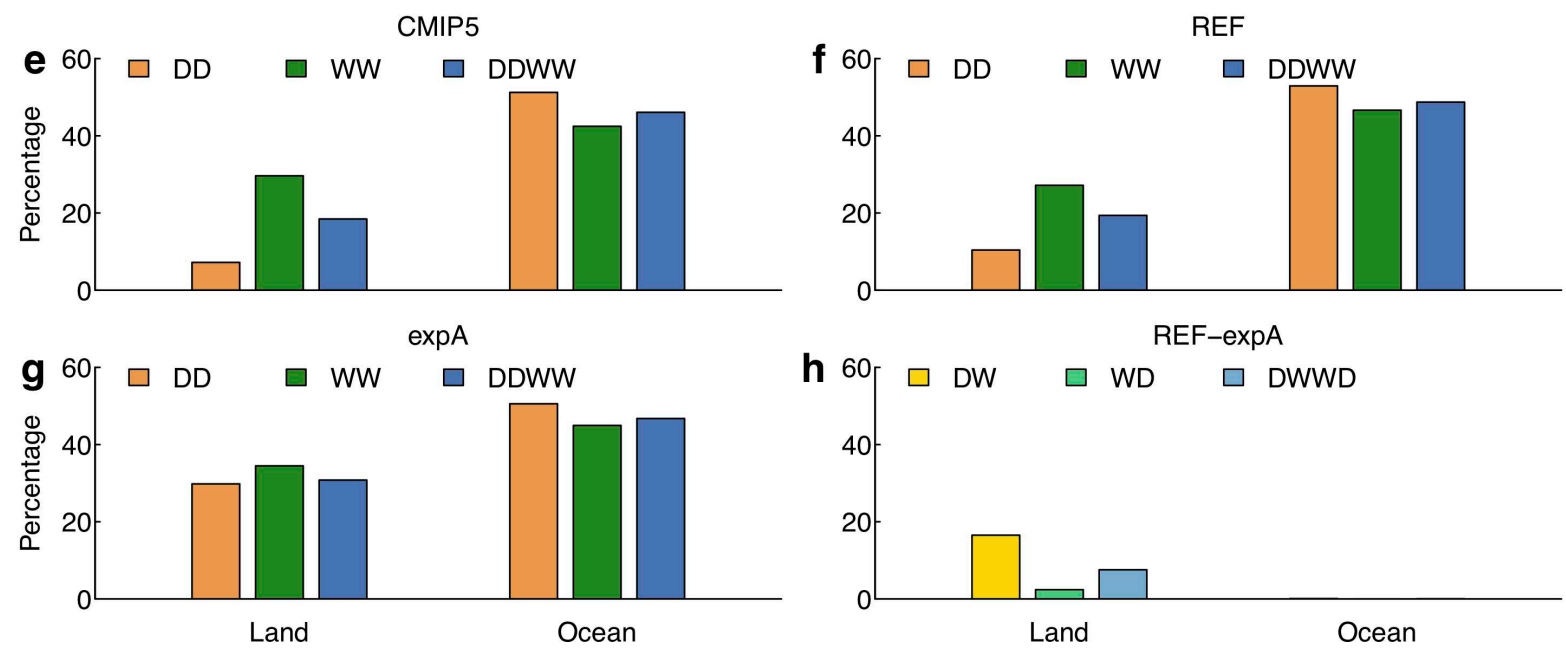

675 Extended Data Fig. 2 | Global distribution of dry and wet regions and assessment of the

676 “dry-get-drier, and wet-get-wetter" paradigm. a-d, Global distribution of dry and wet regions

677 in CMIP5 models (a-b), and GLACE-CMIP5 models (c-d). e-h, Percentages of the dry and wet

678 regions that show significant P-E changes in CMIP5 and GLACE-CMIP5 in Fig. 1. DD (WW)

679 represents the percentage of dry (wet) regions that show significant P-E declines (increases). DW

680 (WD) represents the percentage of dry (wet) regions that show significant P-E increases

681 (decreases). DDWW (DWWD) represents the percentage of land or ocean regions with DD and 682 WW (DW and WD). Antarctica is excluded from the land regions. 

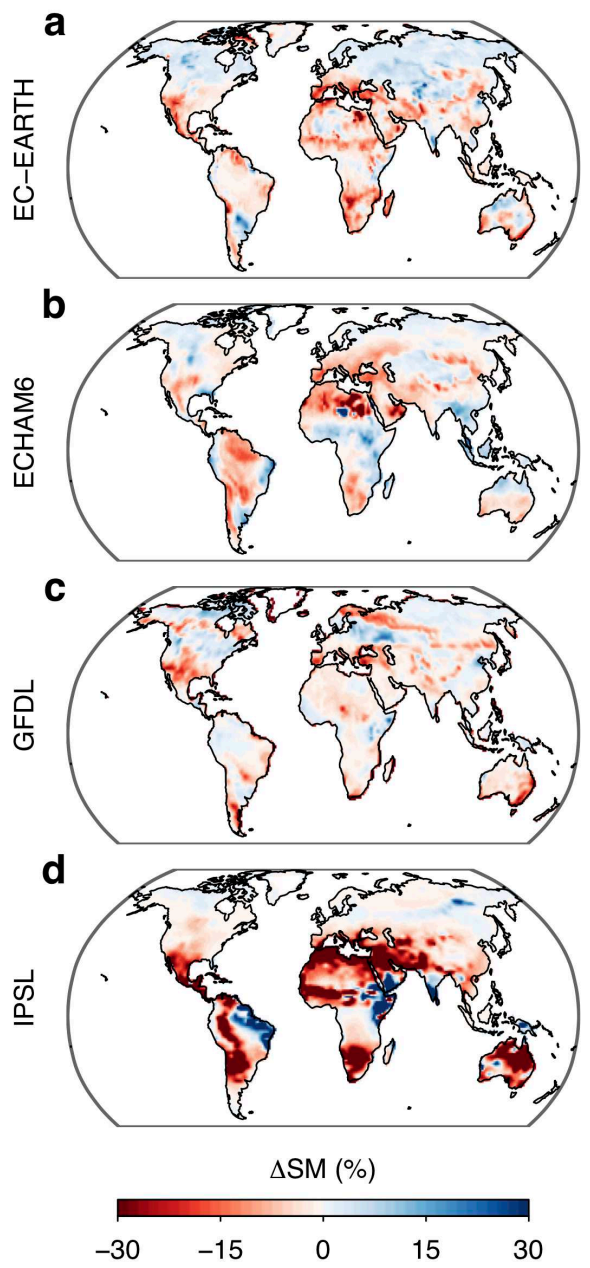

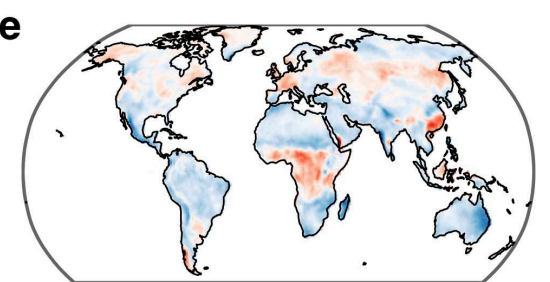

f

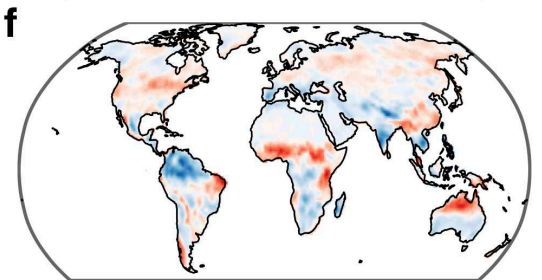

g

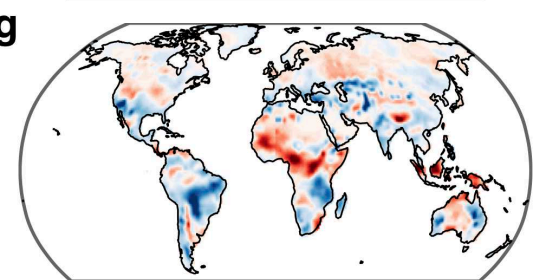

h

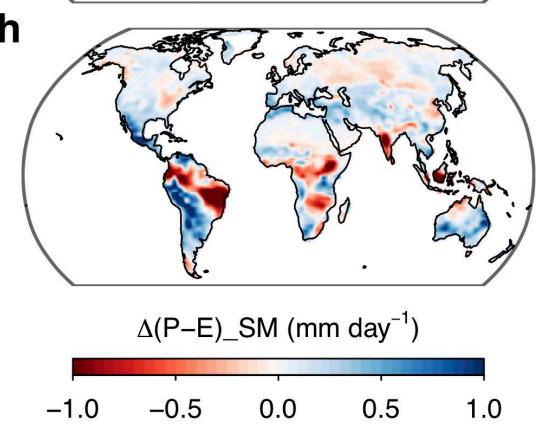

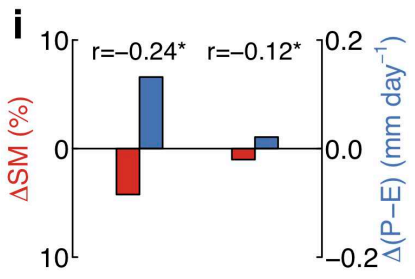
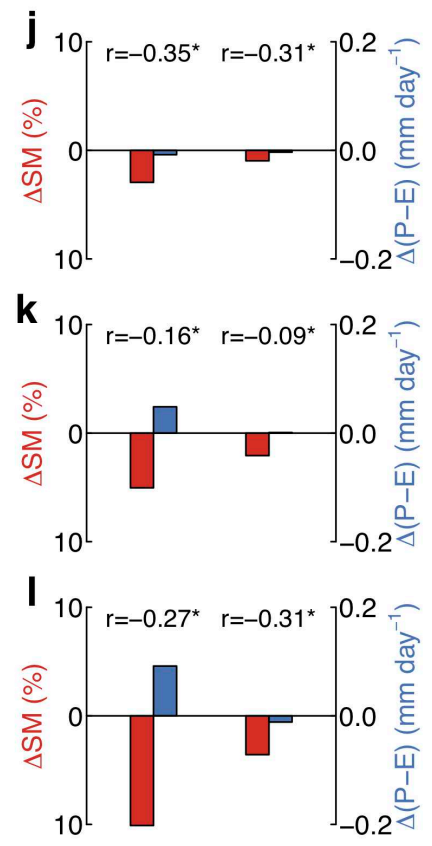

Drylands Non-drylands

684 Extended Data Fig. 3 | Future SM changes and associated P-E changes in the four GLACE-

685 CMIP5 models. a-d, Percent changes in SM between historical (1971-2000) and future (2071686 2100) periods. e-h, Future changes in P-E induced by SM changes. i-l, Mean changes in SM and 687 P-E for the drylands and non-drylands. The spatial correlation coefficient ( $\mathrm{r}$ ) between changes in $688 \mathrm{SM}$ and P-E over the drylands (left) and non-drylands (right) are also shown. All the correlation 689 coefficients are statistically significant at the $0.001(*)$ level following the Student's t-test. 

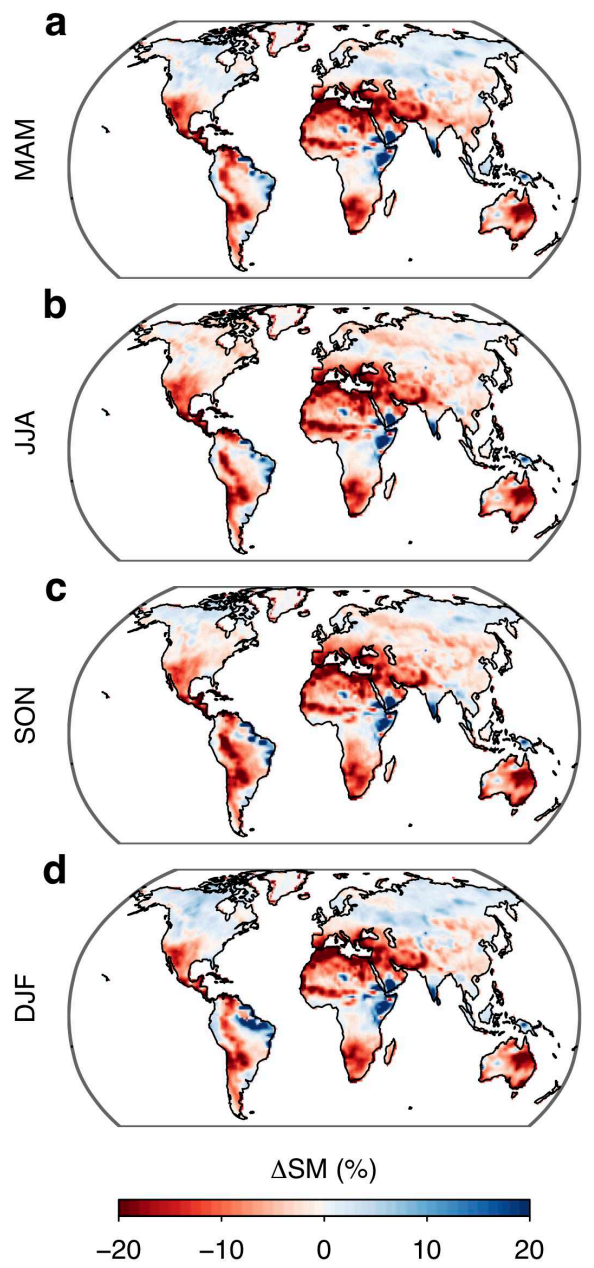

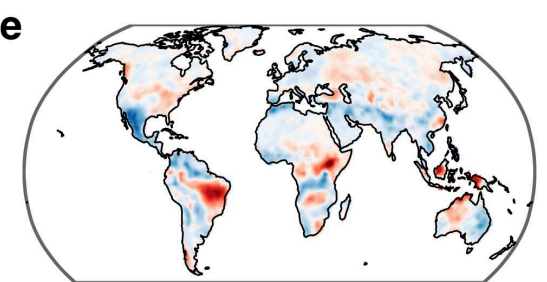

$\mathbf{f}$
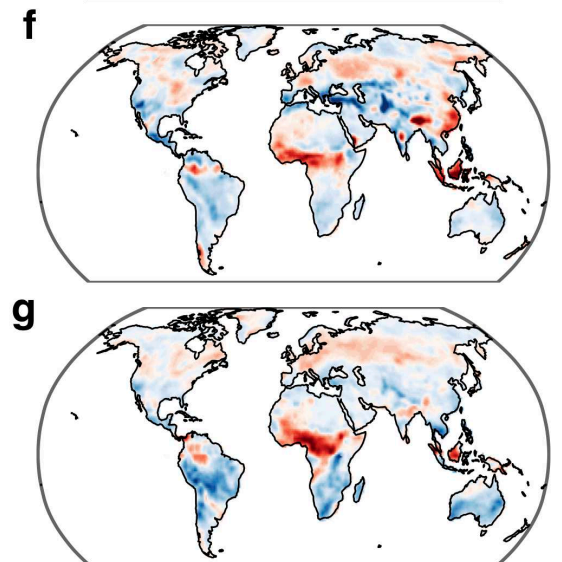

h

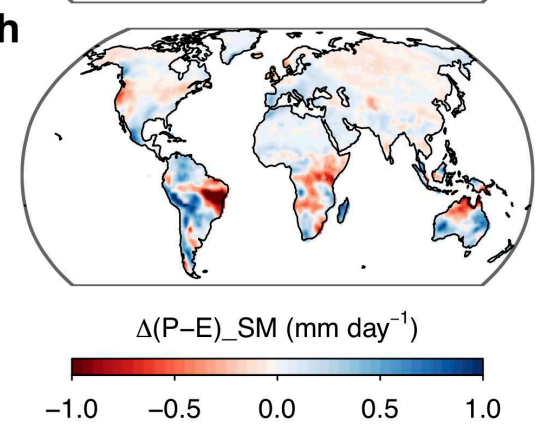

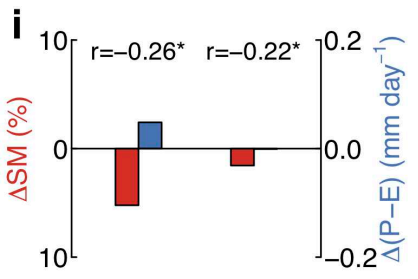
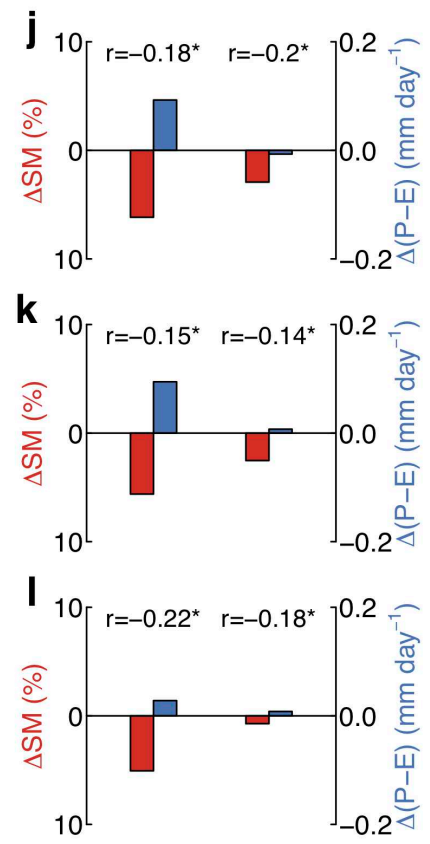

Drylands Non-drylands

Extended Data Fig. 4 | Future SM changes and associated P-E changes for each season in

GLACE-CMIP5. a-d, Multi-model mean percent changes in SM between historical (1971-2000)

694 changes. i-l, Mean changes in SM and P-E for the drylands and non-drylands. The spatial correlation coefficient (r) between changes in SM and P-E over the drylands (left) and non$0.001(*)$ level following the Student's t-test. 


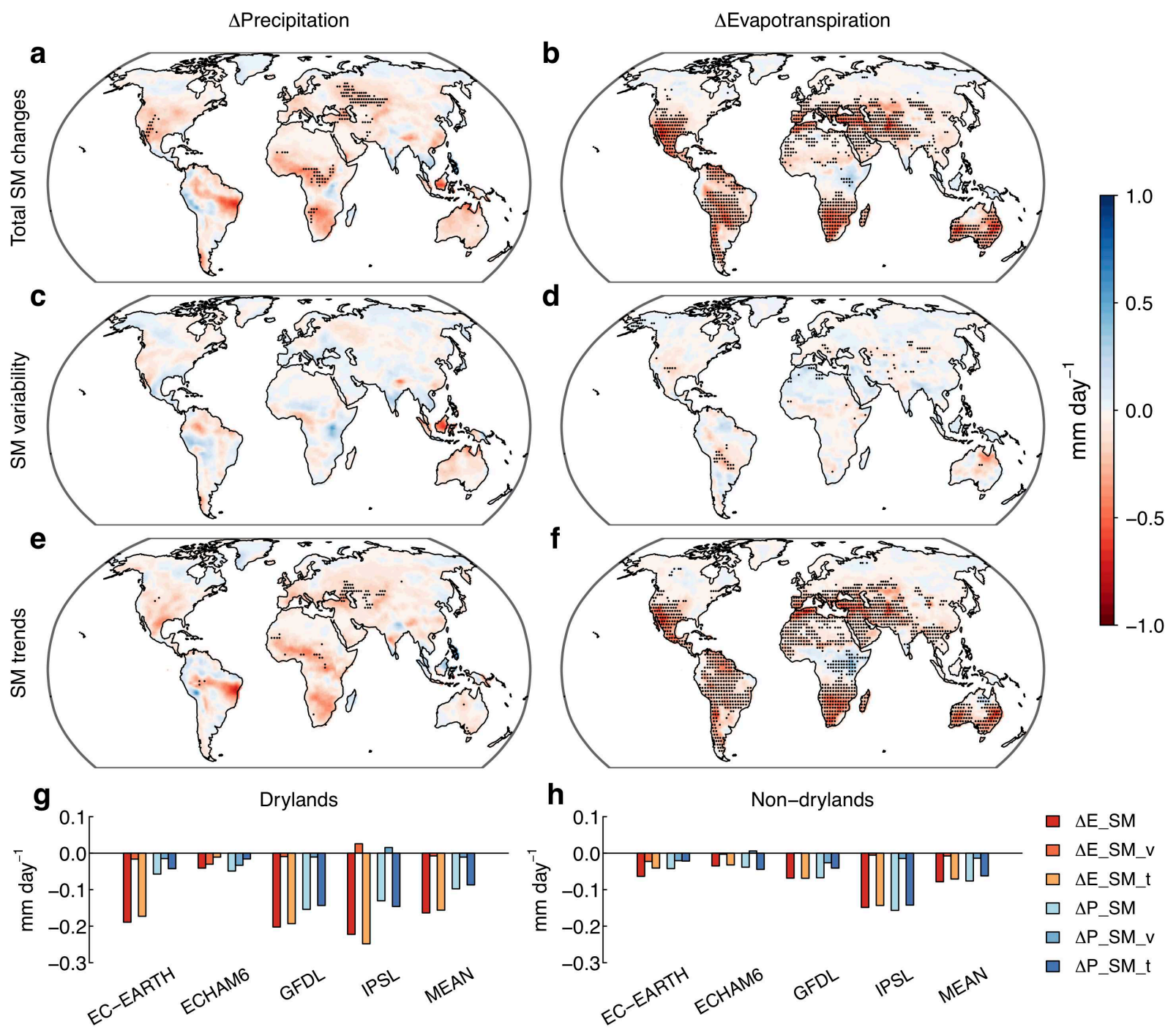

Extended Data Fig. 5 | SM impacts on precipitation and evapotranspiration changes in the

four GLACE-CMIP5 models. a-b, SM induced changes $(\Delta)$ in precipitation (a) and

701 evapotranspiration (b) between historical (1971-2000) and future (2071-2100) periods (future

702 minus historical values). c-f, The same as a-b, but for the effects of SM variability (c-d) and SM 703 trends (e-f). g-h, Contributions of total SM changes, SM variability (SM_v), and SM trends (SM_t) 704 to precipitation and evapotranspiration changes across drylands (g) and non-drylands (h) in the 705 four models. Stippling denotes regions where the changes in precipitation and evapotranspiration 706 are significant at the 95\% level (Student's t-test) and the sign of the change is consistent with the sign of multi-model means (as shown in the figures) in at least three of the four models. 
a
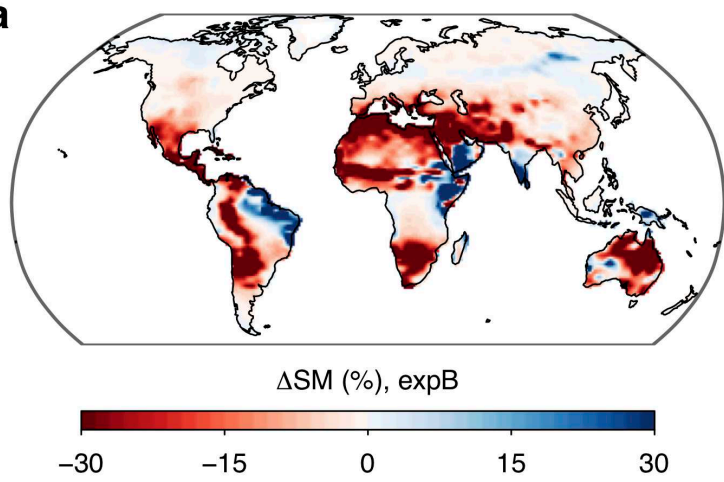

c

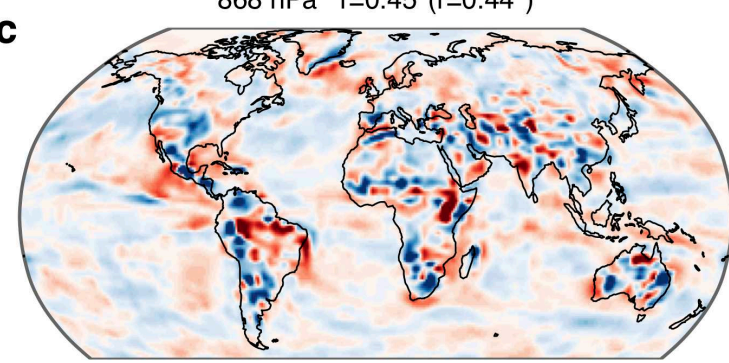

e

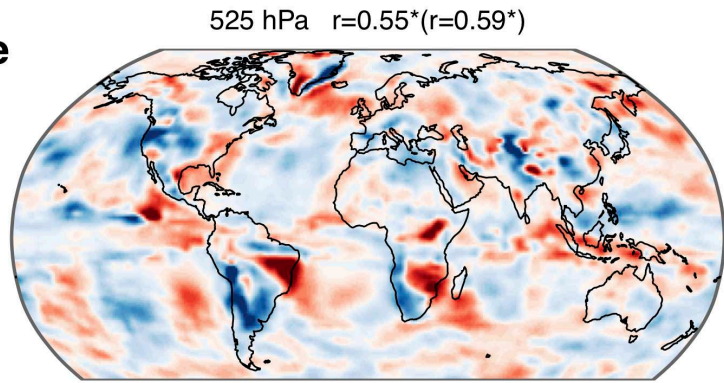

b
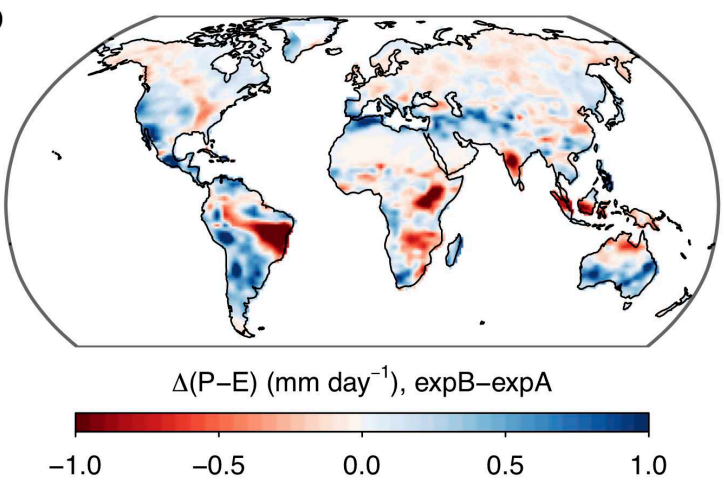

d

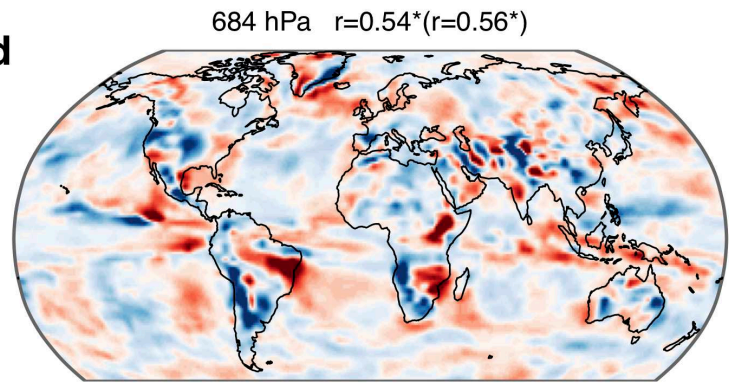

f

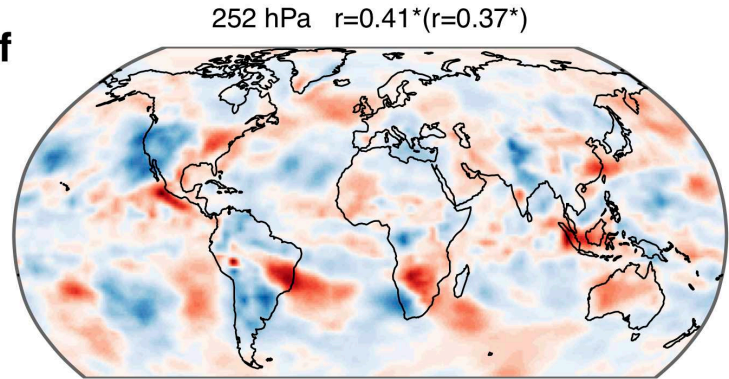

$-\Delta \omega\left(\mathrm{hPa}\right.$ day $\left.^{-1}\right), \operatorname{expB}-\exp \mathrm{A}$

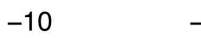

$-5$

0

5

10

Extended Data Fig. 6 | Soil moisture effects on vertical ascent in the IPSL model. a, Percent

710 changes of SM in expB (SM trends) between historical (1971-2000) and future (2071-2100)

711 periods. b, Future changes in P-E induced by SM trends (expB-expA). c-f, Changes in the spatial

712 pattern of negative pressure velocity $(-\Delta \omega$, expB-expA) at different pressure levels of the

713 troposphere. The spatial correlation coefficient between changes in P-E and negative pressure

714 velocity over land (drylands in parentheses) are also shown in c-f. All the correlation coefficients

715 are statistically significant at the $0.001\left(^{*}\right)$ level following the Student's t-test. 

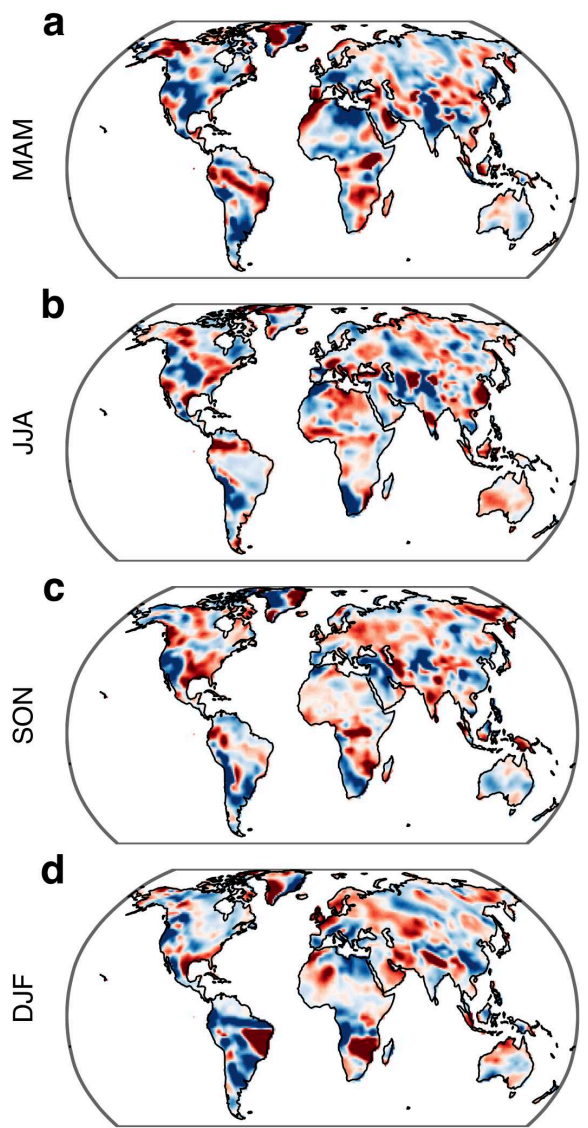

$-\Delta \omega\left(\mathrm{hPa}\right.$ day $\left.^{-1}\right), \operatorname{expB-expA}$

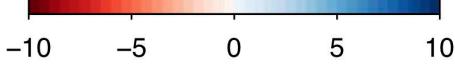

e

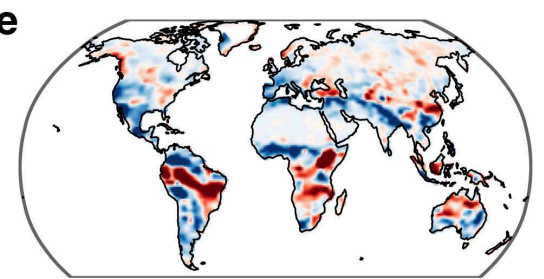

$\mathbf{f}$

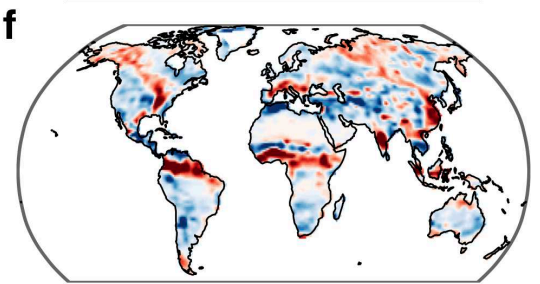

g

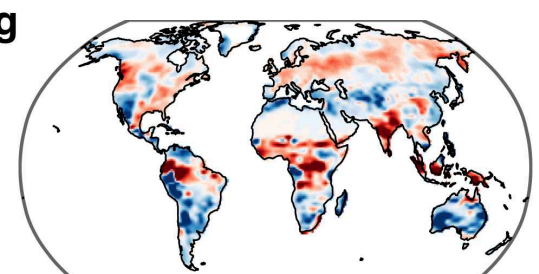

$\mathbf{h}$

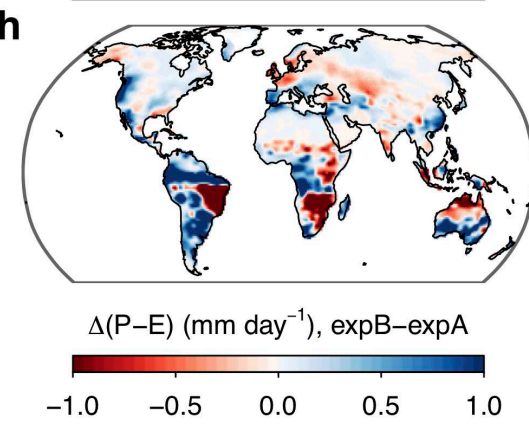

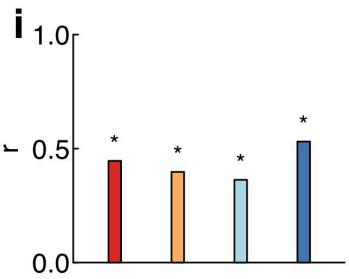
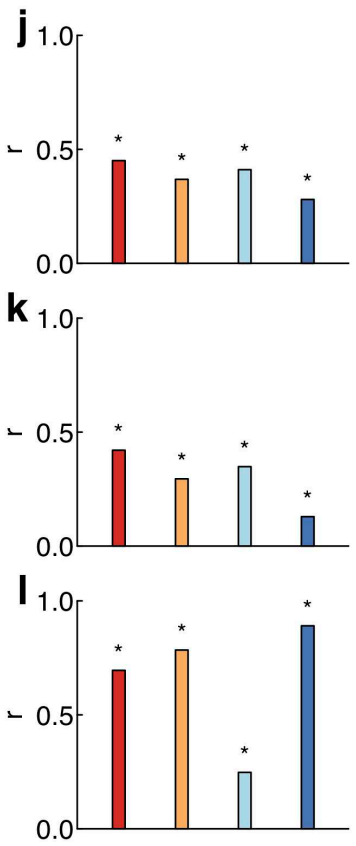

$\square$ Global Land

$\square$ Drylands

$\square$ Northern Drylands

$\square$ Southern Drylands

Extended Data Fig. 7 | Soil moisture effects on vertical ascent for each season in the IPSL

718 model. a-h, Spatial patterns of future changes in negative pressure velocity $(-\Delta \omega, 525 \mathrm{hPa}, \mathbf{a}-\mathbf{d})$

719 and P-E (e-h) between historical (1971-2000) and future (2071-2100) periods due to SM trends

720 (expB-expA) in the four seasons. i-l, Spatial correlation coefficients between future changes in P-

721 E and negative pressure velocity over land and drylands. All the correlation coefficients are

722 statistically significant at the $0.001(*)$ level following the Student's t-test. 


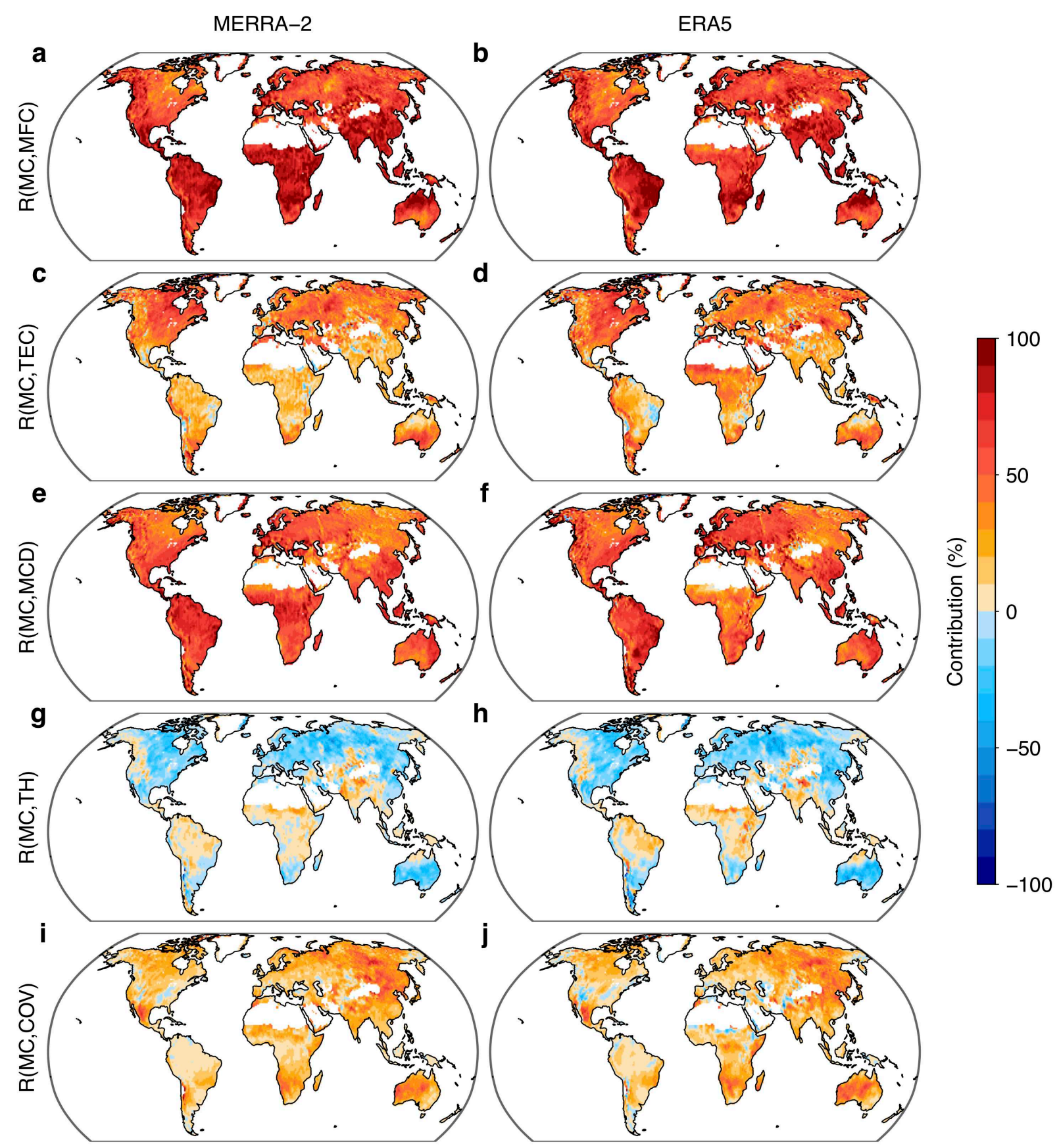

724 Extended Data Fig. 8 | Contributions of each component to moisture convergence variations.

$725 \mathbf{a}, \mathbf{b}$, Contribution of the mean flow convergence to moisture convergence variations (R(MC,MFC))

726 in MERRA-2 (1980-2018) and ERA5 (1979-2018). c-j, The same as a,b, but for contributions of

727 the transient eddy convergence $(\mathrm{R}(\mathrm{MC}, \mathrm{TEC}))(\mathbf{c}, \mathbf{d})$, the mean circulation dynamic component

$728(\mathrm{R}(\mathrm{MC}, \mathrm{MCD}))(\mathbf{e}, \mathbf{f})$, the thermodynamic component $(\mathrm{R}(\mathrm{MC}, \mathrm{TH}))(\mathbf{g}, \mathbf{h})$, and the covariation 729 component $(\mathrm{R}(\mathrm{MC}, \mathrm{COV}))(\mathbf{i}, \mathbf{j})$. 


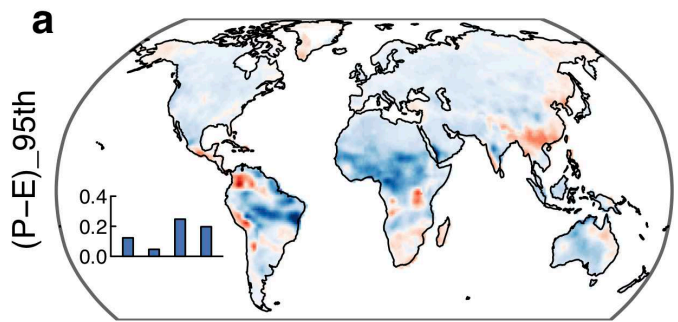

b

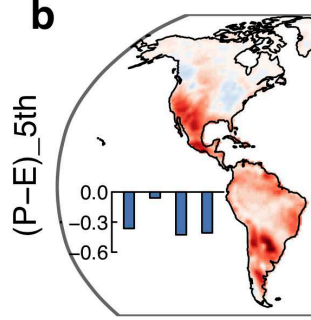

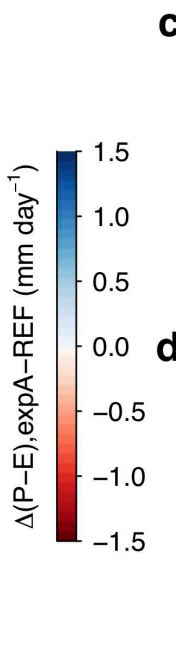

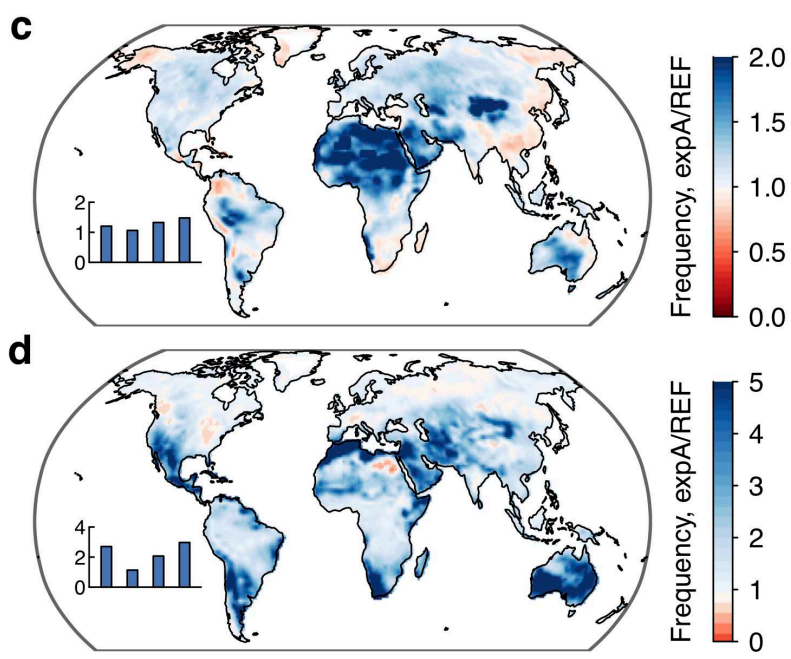

731 Extended Data Fig. 9 | Multi-model mean differences in monthly P-E extremes between expA

732 and REF in GLACE-CMIP5. a-b, Differences in $95^{\text {th }}$ percentile P-E (a), and $5^{\text {th }}$ percentile P-E

733 (b) between expA and REF over the period of 1950-2100. c-d, Ratio of the frequency of extreme

734 high P-E (above 95 ${ }^{\text {th }}$ percentile P-E in REF) (c) and extreme low P-E (below $5^{\text {th }}$ percentile P-E in 735 REF) (d) between expA and REF. The inset barplots show area-weighted means for the four 736 models (EC-EARTH, ECHAM6, GFDL, IPSL) in GLACE-CMIP5. 


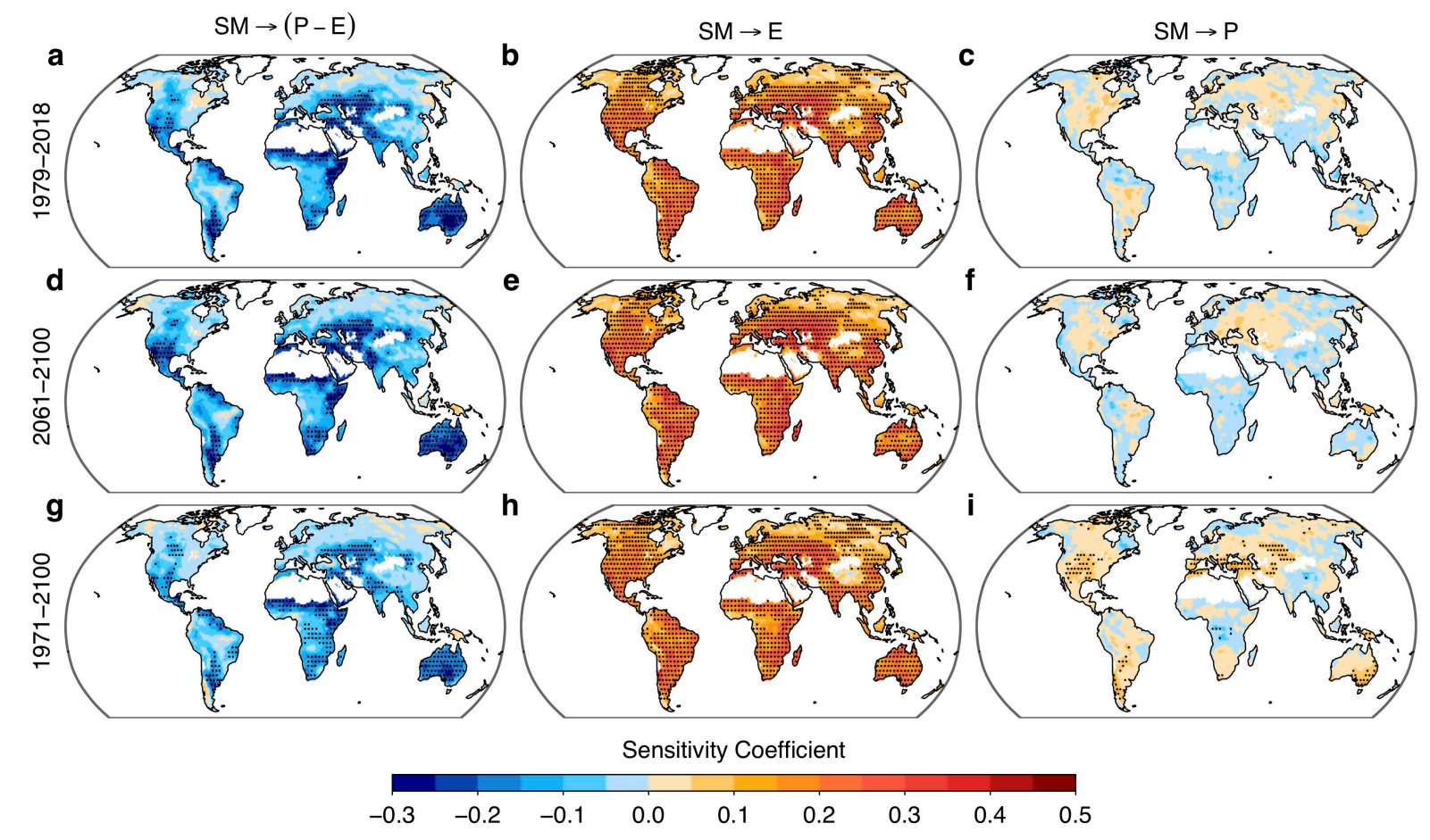

Extended Data Fig. 10 | Soil moisture feedbacks on water availability in GLACE-CMIP5

739 models. Mean sensitivity coefficients for soil moisture $(\mathrm{SM}) \rightarrow$ precipitation minus

740 evapotranspiration (P-E), $\mathrm{SM} \rightarrow$ evapotranspiration $(\mathrm{E})$ and $\mathrm{SM} \rightarrow$ precipitation (P) identified based

741 on REF of the four GLACE-CMIP5 models during 1979-2018 (a-c), 2061-2100 (d-f) and 1971-

$7422100(\mathbf{g}-\mathbf{i})$. The sensitivity coefficient for $\mathrm{X} \rightarrow \mathrm{Y}$ denotes the partial derivative of standardized $\mathrm{Y}$ to

743 standardized $\mathrm{X}$ in the previous month, where the seasonal cycles and long-term trends in $\mathrm{X}$ and $\mathrm{Y}$

744 are removed (a-f). In $\mathbf{g - i}$, the seasonal cycles of $\mathrm{X}$ and $\mathrm{Y}$ are removed but the trends in $\mathrm{X}$ and $\mathrm{Y}$

745 are retained. Stippling denotes regions where the sensitivity coefficient is significant at the $95 \%$

746 level according to a bootstrap test and the sign of the sensitivity coefficient is consistent with the

747 sign of multi-model means (as shown in the figure) in at least three of the four GLACE-CMIP5

748 models. 
749 Table S1. List of the 35 CMIP5 models (historical and RCP8.5 simulations) used in this study.

\begin{tabular}{|c|c|c|}
\hline Model Name & Institute ID & Modeling Center \\
\hline ACCESS1-0 & \multirow[b]{2}{*}{ CSIRO-BOM } & \multirow{2}{*}{$\begin{array}{c}\text { Commonwealth Scientific and Industrial Research } \\
\text { Organization (CSIRO) and Bureau of Meteorology } \\
\text { CSIRO-BOM (BOM), Australia }\end{array}$} \\
\hline ACCESS1-3 & & \\
\hline bcc-csm $1-1$ & \multirow[t]{2}{*}{$\mathrm{BCC}$} & \multirow{2}{*}{$\begin{array}{l}\text { Beijing Climate Center, China Meteorological } \\
\text { Administration }\end{array}$} \\
\hline bcc-csm1-1-m & & \\
\hline BNU-ESM & GCESS & $\begin{array}{l}\text { College of Global Change and Earth System } \\
\text { Science, Beijing Normal University }\end{array}$ \\
\hline CanESM2 & CCCMA & Canadian Center for Climate Modeling and Analysis \\
\hline CCSM4 & NCAR & National Center for Atmospheric Research \\
\hline CESM1-BGC & NSF-DOE-NCAR & Community Earth System Model Contributors \\
\hline CMCC-CM & \multirow{2}{*}{$\mathrm{CMCC}$} & \multirow{2}{*}{$\begin{array}{l}\text { Centro Euro-Mediterraneo per I Cambiamenti } \\
\text { Climatici }\end{array}$} \\
\hline CMCC-CMS & & \\
\hline CNRM-CM5 & $\begin{array}{l}\text { CNRM- } \\
\text { CERFACS }\end{array}$ & $\begin{array}{c}\text { Centre National de Recherches Météorologiques / } \\
\text { Centre Européen de Recherche et Formation } \\
\text { Avancée en Calcul Scientifique }\end{array}$ \\
\hline CSIRO-Mk3-6-0 & CSIRO-QCCCE & $\begin{array}{c}\text { Commonwealth Scientific and Industrial Research } \\
\text { Organization in collaboration with Queensland } \\
\text { Climate Change Centre of Excellence }\end{array}$ \\
\hline GFDL-CM3 & \multirow{3}{*}{ NOAA GFDL } & \multirow{3}{*}{ NOAA Geophysical Fluid Dynamics Laboratory } \\
\hline GFDL-ESM2G & & \\
\hline GFDL-ESM2M & & \\
\hline GISS-E2-H & \multirow{4}{*}{ NASA GISS } & \multirow{4}{*}{ NASA Goddard Institute for Space Studies } \\
\hline GISS-E2-H-CC & & \\
\hline GISS-E2-R & & \\
\hline GISS-E2-R-CC & & \\
\hline HadGEM2-AO & NIMR/KMA & $\begin{array}{c}\text { National Institute of Meteorological Research/Korea } \\
\text { Meteorological Administration }\end{array}$ \\
\hline HadGEM2-CC & \multirow{2}{*}{$\begin{array}{c}\text { MOHC } \\
\text { (additional } \\
\text { realizations by } \\
\text { INPE) }\end{array}$} & \multirow{2}{*}{$\begin{array}{l}\text { Met Office Hadley Centre (additional HadGEM2-ES } \\
\text { realizations contributed by Instituto Nacional de } \\
\text { Pesquisas Espaciais) }\end{array}$} \\
\hline HadGEM2-ES & & \\
\hline inmcm4 & INM & Institute for Numerical Mathematics \\
\hline IPSL-CM5A-LR & \multirow[b]{2}{*}{ IPSL } & \multirow[b]{2}{*}{ Institut Pierre Simon Laplace } \\
\hline $\begin{array}{l}\text { IPSL-CM5A- } \\
\text { MR }\end{array}$ & & \\
\hline
\end{tabular}




\begin{tabular}{|c|c|c|}
\hline IPSL-CM5B-LR & & \\
\hline MIROC5 & MIROC & $\begin{array}{l}\text { Atmosphere and Ocean Research Institute (The } \\
\text { University of Tokyo), National Institute for } \\
\text { Environmental Studies, and Japan Agency for } \\
\text { Marine-Earth Science and Technology }\end{array}$ \\
\hline $\begin{array}{l}\text { MIROC-ESM } \\
\text { MIROC-ESM- } \\
\text { CHEM }\end{array}$ & MIROC & $\begin{array}{c}\text { Japan Agency for Marine-Earth Science and } \\
\text { Technology, Atmosphere and Ocean Research } \\
\text { Institute (The University of Tokyo), and National } \\
\text { Institute for Environmental Studies }\end{array}$ \\
\hline $\begin{array}{c}\text { MPI-ESM-LR } \\
\text { MPI-ESM-MR }\end{array}$ & MPI-M & Max Planck Institute for Meteorology \\
\hline $\begin{array}{c}\text { MRI-CGCM3 } \\
\text { MRI-ESM1 }\end{array}$ & MRI & Meteorological Research Institute \\
\hline$\frac{\text { NorESM1-M }}{\text { NorESM1-ME }}$ & $\mathrm{NCC}$ & Norwegian Climate Centre \\
\hline
\end{tabular}


CMIP5

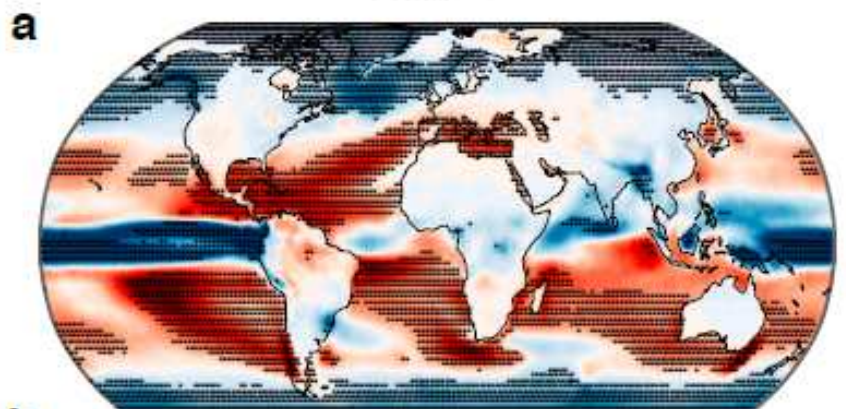

b

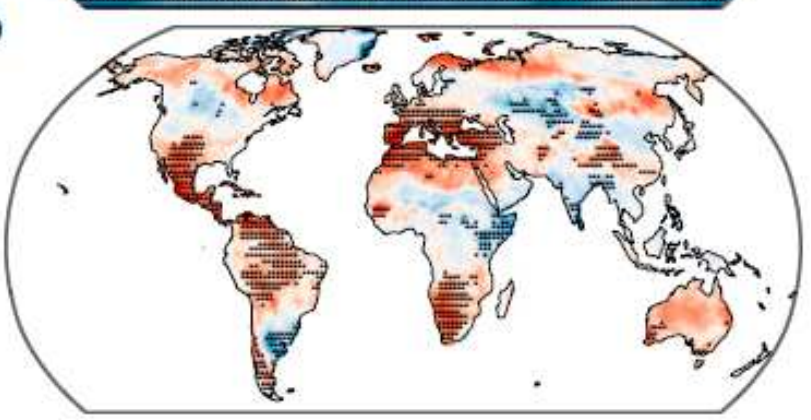

$\operatorname{expA}$ (Non-SM effect)
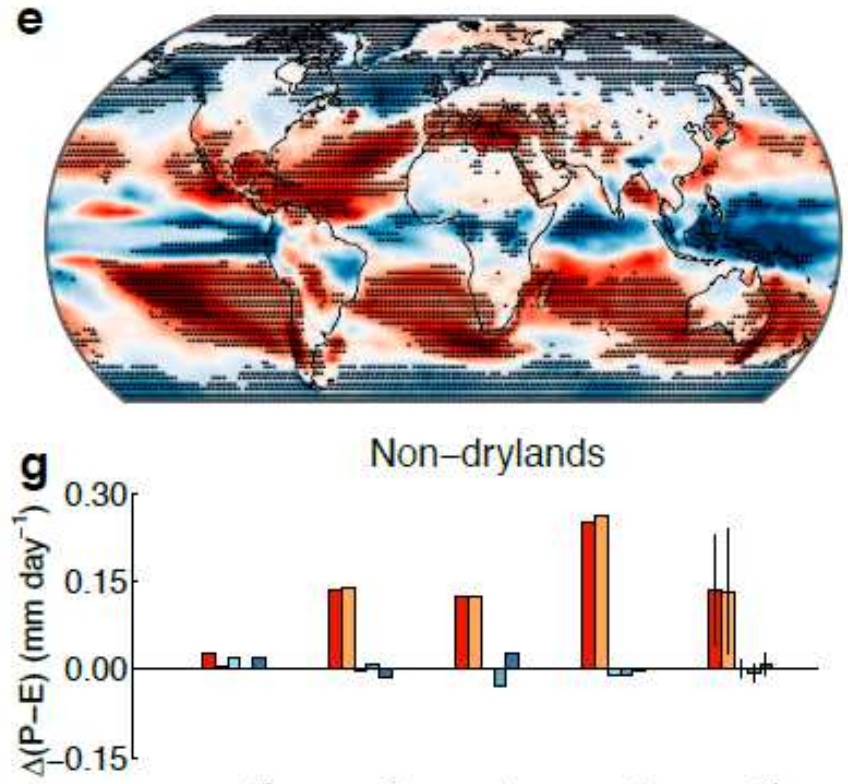

ECEEATH ECHAMG GFDL IPSL MEAN
REF (Total change)
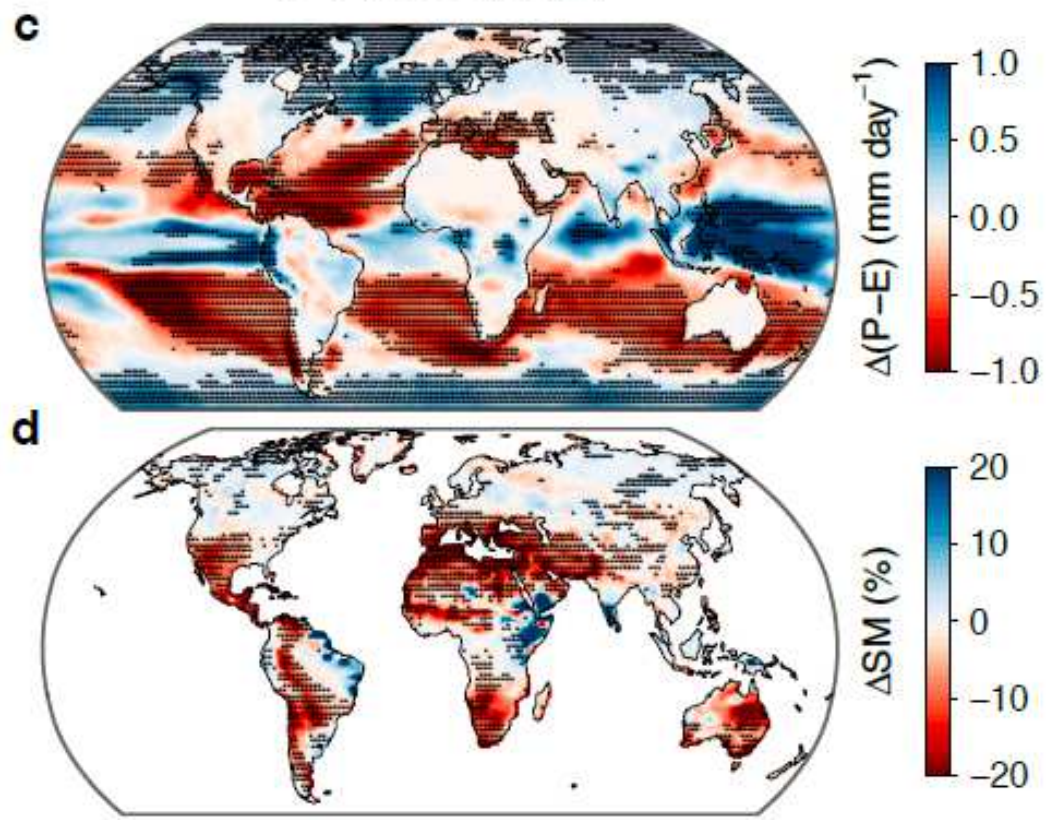

REF-expA (SM effect)

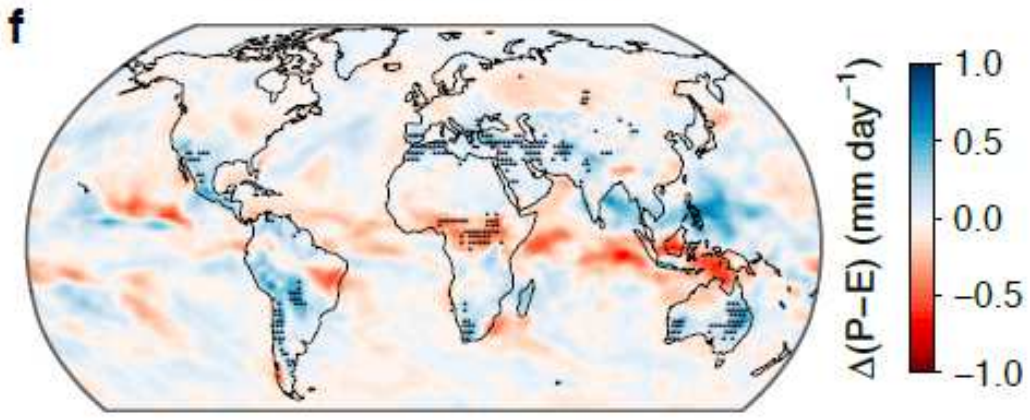

Drylands

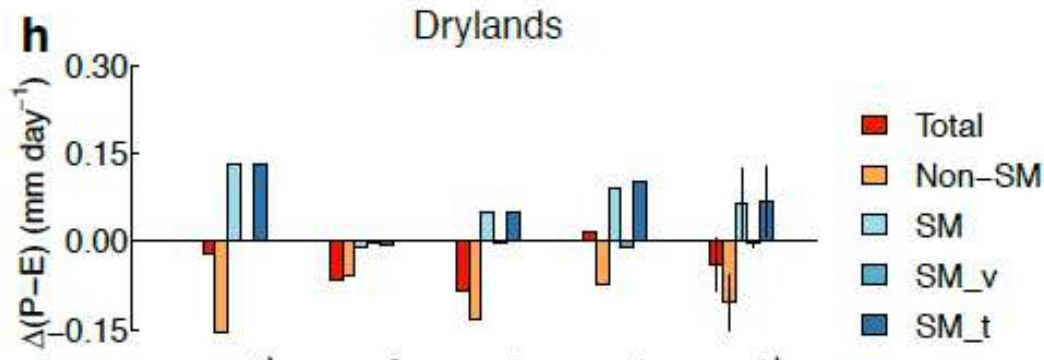
EC-EAPTH ECHAMG GFDL IPSL MEAN

\section{Figure 1}

Multi-model mean annual changes in surface water availability and soil moisture. a-b, Changes in precipitation minus evapotranspiration (delta(P-E)) and percent changes in total soil moisture (deltaSM) between historical (1971-2000) and future (2071-2100, RCP8.5) periods (future minus historical values) in 35 CMIP5 models. $c-f$, The same as a-b, but for REF of the four GLACE-CMIP5 models (c-d), and delta(P-E) induced by non-SM factors (expA, e) and SM (REF expA, f). g-h, Total area-weighted delta(P-E) 
and the contributions from non-SM factors, total SM changes, SM variability (SM_v), and SM trends $\left(S M \_t\right)$ across non-drylands $(\mathrm{g})$ and drylands $(\mathrm{h})$ in the four GLACE-CMIP5 models. The error bar shows the standard deviation of delta(P-E) across the four models. Stippling denotes regions where the change in P-E is significant at the $95 \%$ level (Student's t-test) and the sign of the change is consistent with the sign of multi-model means (as shown in the figure) in at least 21 of the $35(60 \%)$ CMIP5 models (a-b), and at least three of the four GLACE-CMIP5 models (c-f). Note: The designations employed and the presentation of the material on this map do not imply the expression of any opinion whatsoever on the part of Research Square concerning the legal status of any country, territory, city or area or of its authorities, or concerning the delimitation of its frontiers or boundaries. This map has been provided by the authors.
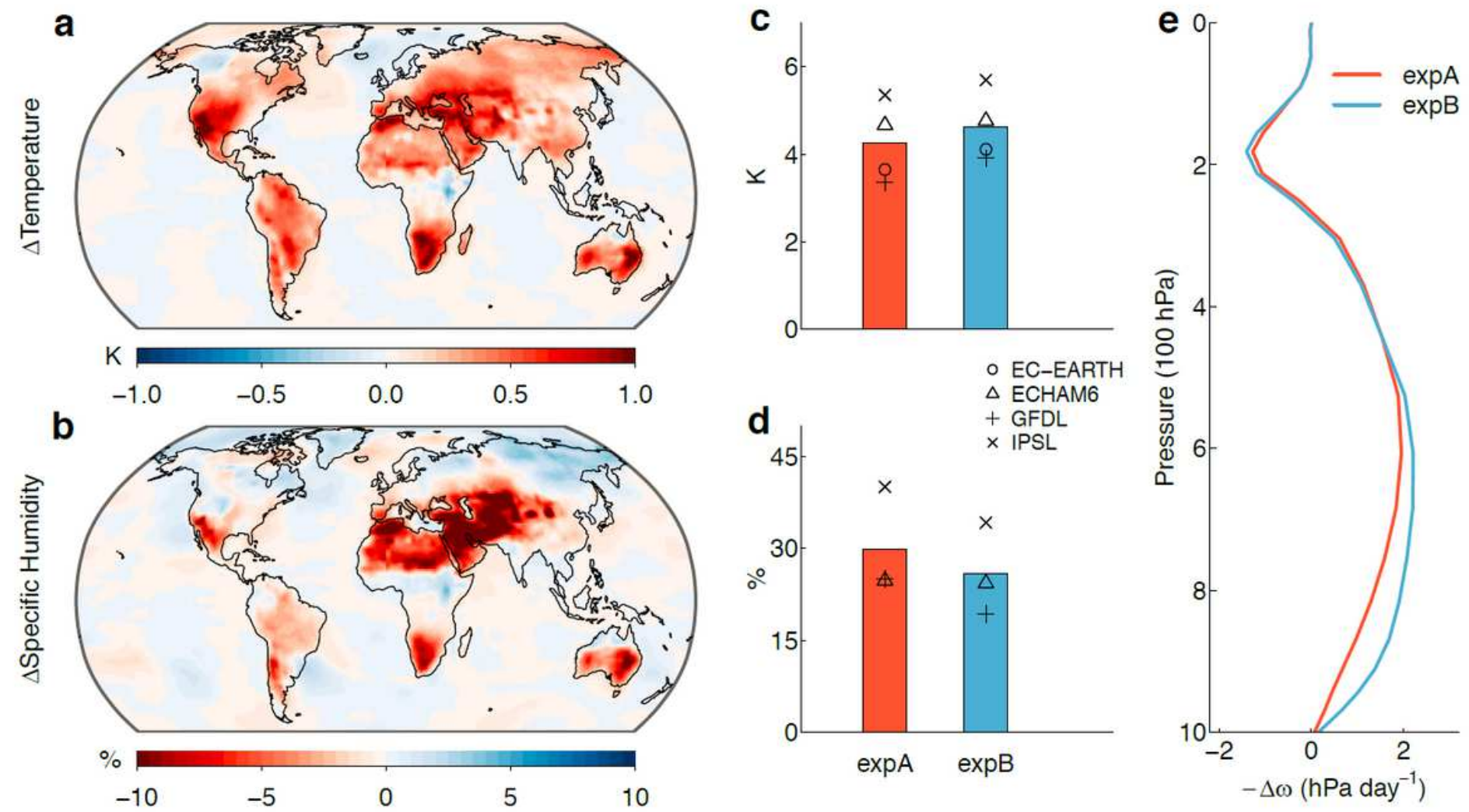

Figure 2

Soil moisture effects on changes in temperature, specific humidity, and vertical ascent in GLACE-CMIP5. a,b, Multi-model mean soil moisture effects (expB-expA) on projected changes (delta) in temperature and specific humidity from historical (1971-2000) to future (2071-2100) periods (future minus historical values). c,d, Projected changes in temperature and specific humidity over drylands in expA and expB (bars: multi-model mean, symbols: individual models, specific humidity is not available in EC-EARTH). Changes to specific humidity are expressed fractionally relative to their historic period values (in percentages). e, Projected changes in negative pressure velocity (-deltaw) over drylands in expA and expB for the IPSL model. Note: The designations employed and the presentation of the material on this map do not imply the expression of any opinion whatsoever on the part of Research Square concerning the legal 
status of any country, territory, city or area or of its authorities, or concerning the delimitation of its frontiers or boundaries. This map has been provided by the authors.

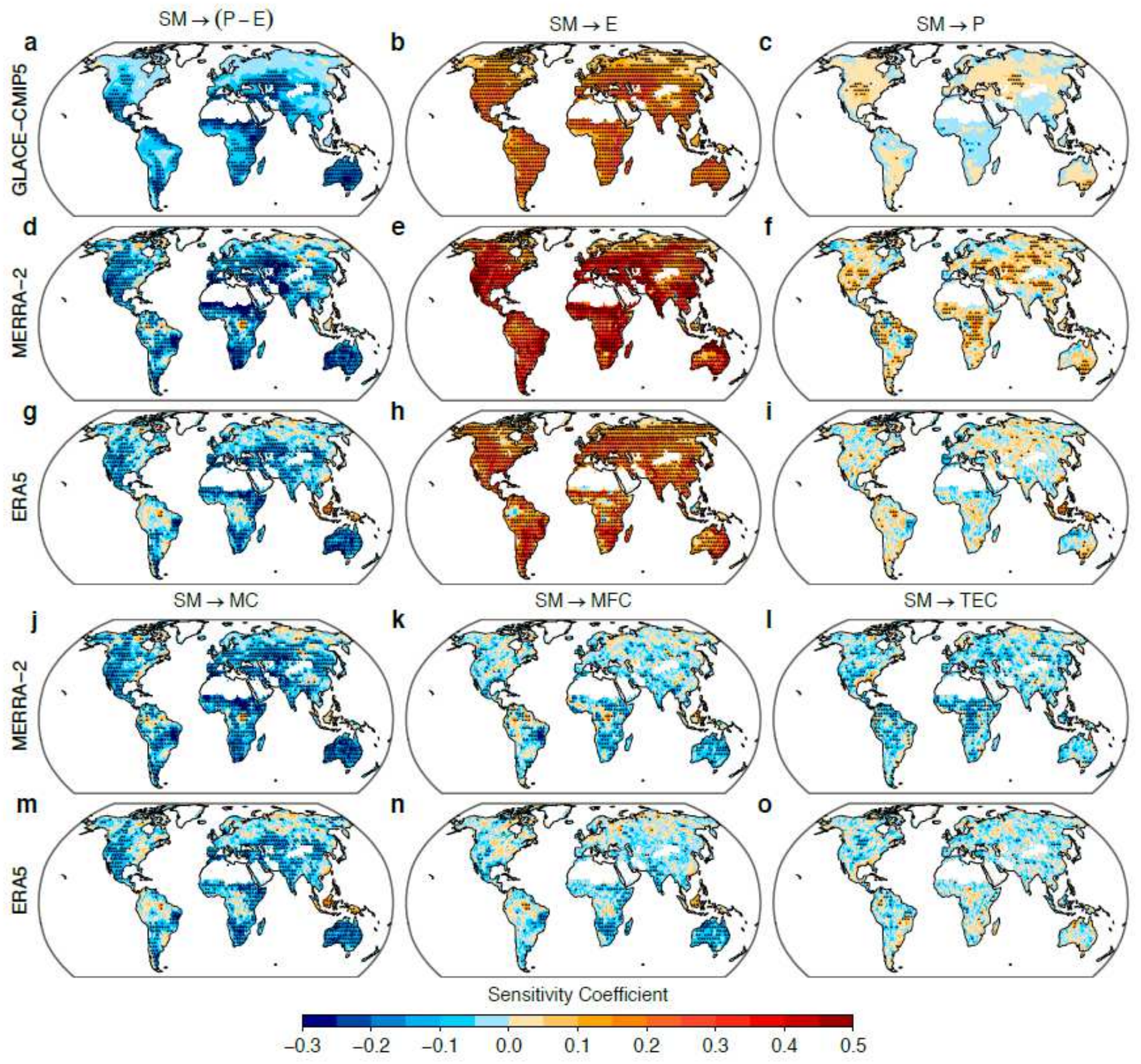

Figure 3

Soil moisture feedbacks on water availability in GLACE-CMIP5 models and reanalysis datasets. a-f, Sensitivity coefficients for soil moisture (SM)->precipitation minus evapotranspiration (P-E), SM>evapotranspiration (E), and SM->precipitation (P) identified based on REF of the four GLACE-CMIP5 models (1971-2100) (a-c), MERRA-2 (1980-2018) (d f), and ERA5 (1979-2018) (g-i). Mean values of the sensitivity coefficients produced by the four models are shown in a-c. j-o, the same as d-i, but for SM>moisture convergence (MC) (j,m), SM->mean flow convergence (MFC) $(k, n)$, and SM->transient eddy 
convergence (TEC) $(I, 0)$. The sensitivity coefficient for $X->Y$ denotes the partial derivative of standardized $Y$ to standardized $X$ in the previous month, where the seasonal cycles and long-term trends in $X$ and $Y$ are removed. Stippling denotes regions where the sensitivity coefficient is significant at the $95 \%$ level according to a bootstrap test. In a-c, stippling denotes regions where the sensitivity coefficient is significant at the $95 \%$ level and the sign of the sensitivity coefficient is consistent with the sign of multimodel means (as shown in the figure) in at least three of the four GLACE CMIP5 models. Note: The designations employed and the presentation of the material on this map do not imply the expression of any opinion whatsoever on the part of Research Square concerning the legal status of any country, territory, city or area or of its authorities, or concerning the delimitation of its frontiers or boundaries. This map has been provided by the authors. 


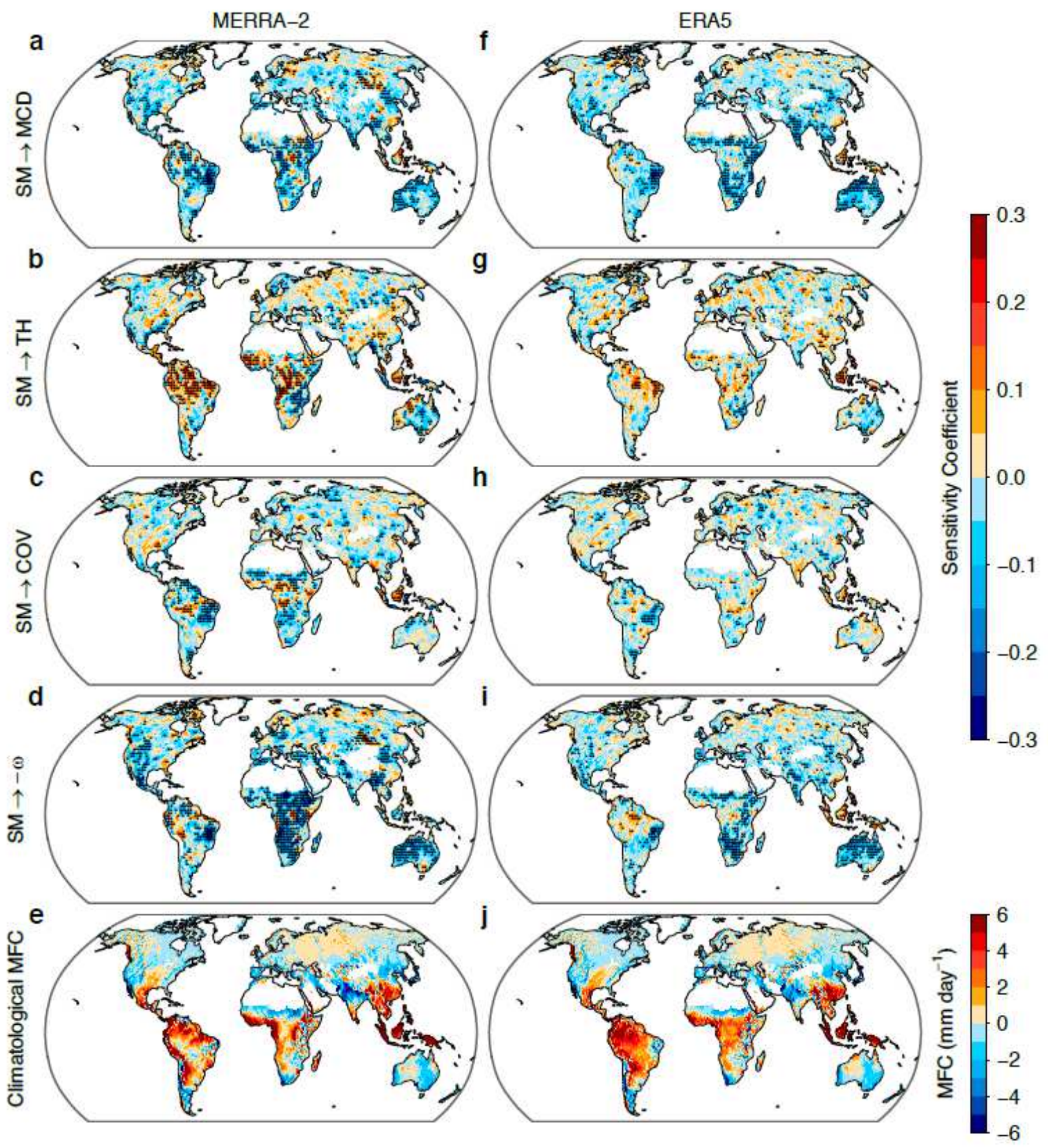

Figure 4

Soil moisture effects on the three components of mean flow convergence. a-e, Sensitivity coefficients for soil moisture (SM)->mean circulation dynamic component (MCD) (a), SM->thermodynamic component (TH) (b), SM->covariation component (COV) (c), SM->negative pressure velocity (-w) at $700 \mathrm{hPa}$ (middle troposphere) (d), and climatological monthly mean flow convergence (MFC) (e) in MERRA-2 (1980-2018). $f-j$, the same as a-e, but for ERA5 (1979-2018). The sensitivity coefficient for $X->Y$ denotes the partial 
derivative of standardized $Y$ to standardized $X$ in the previous month, where the seasonal cycles and long-term trends in $\mathrm{X}$ and $\mathrm{Y}$ are removed. Stippling in a- $\mathrm{d}$ and $\mathrm{f}$-i denotes regions where the sensitivity coefficient is significant at the $95 \%$ level according to a bootstrap test. Note: The designations employed and the presentation of the material on this map do not imply the expression of any opinion whatsoever on the part of Research Square concerning the legal status of any country, territory, city or area or of its authorities, or concerning the delimitation of its frontiers or boundaries. This map has been provided by the authors. 